Aus der Klinik für Hals-Nasen-Ohrenheilkunde

(Prof. Dr. med. D. Beutner)

der Medizinischen Fakultät der Universität Göttingen

\title{
Methylprednisolon zur Behandlung des akuten Hörverlusts im Tiermodell: Eine doppelblinde placebokontrollierte Studie
}

\author{
INAUGURAL-DISSERTATION \\ zur Erlangung des Doktorgrades \\ für Zahnheilkunde \\ der Medizinischen Fakultät der \\ Georg-August-Universität Göttingen \\ vorgelegt von \\ Hendrik Christoph Desinger
}

aus

Bochum

Göttingen 2019 
Dekan:

Referent/in:

Ko-Referent/in:

Drittreferent/in:
Prof. Dr. rer. nat. H. K. Kroemer

Prof. Dr. med. M. Canis

Prof. Dr. med. N. Strenzke

Prof. Dr. med. dent. R. Mausberg 
Hiermit erkläre ich, die Dissertation mit dem Titel „Methylprednisolon zur Behandlung des akuten Hörverlusts im Tiermodell: Eine doppelblinde placebokontrollierte Studie" eigenständig angefertigt und keine anderen als die von mir angegebenen Quellen und Hilfsmittel verwendet zu haben.

Göttingen, den

(Unterschrift) 
Teile dieser Doktorarbeit wurden bereits in wissenschaftlichen Magazinen und auf Konferenzen in Form von Postern, Vorträgen und Abstracts vorgestellt.

\section{Originalarbeiten:}

Weiss BG, Bertlich M, Bettag SA, Desinger H, Ihler F, Canis M (2017): Drug-induced Defibrinogenation as New Treatment Approach of Acute Hearing Loss in an Animal Model for Inner Ear Vascular Impairment. Otol Neurotol 38, 648-654

\section{Patentanmeldung:}

Weiss BG, Canis M: Neue Verwendung von Ancrod bei Innenohrerkrankungen. Patentanmeldung beim Deutschen Patent- und Markenamt am 12.05.2015, Anmeldenummer DE 102015107469.9

\section{Poster / Präsentationen / Abstracts:}

Weiss BG, Bertlich M, Bettag SA, Desinger H, Ihler F, Canis M (2015): Medikamentöse Defibrinogenierung als neuer Therapieansatz des akuten Hörverlusts in einem vaskulären Schädigungsmodell des Innenohres in vivo. Herbsttagung der Arbeitsgemeinschaft Deutschsprachiger Audiologen, Neurootologen und Otologen (ADANO), Bern 2015 (https://www.egms.de/static/pdf/journals/cpo/201511/cpo000987.pdf)

Weiss BG, Bertlich M, Bettag SA, Canis M, Desinger H, Ihler F: Medikamentöse Defibrinogenierung zur Therapie des akuten Hörverlusts in einem vaskulären Schädigungsmodell des Innenohres in vivo. 86. Jahresversammlung der DGHNO, Berlin 2015 


\section{Inhaltsverzeichnis}

$\begin{array}{lll}\text { Abbildungsverzeichnis } & \text { IV }\end{array}$

$\begin{array}{ll}\text { Abkürzungsverzeichnis } & \mathrm{V}\end{array}$

1. Einleitung 1

1.1. Vorstellung der Arbeit 1

1.2. Der Hörsturz 1

1.2.1. Pathomechanismen 2

1.2.1.1 Durchblutungsstörung 2

1.2.1.2 Infektion 4

1.3. Diagnostik des Hörsturzes

1.4. Therapie des Hörsturzes mit Glukokortikoiden 6

$\begin{array}{ll}\text { 1.4.1. Kortikosteroidsynthese } & 7\end{array}$

1.5. Fragestellung 8

2. Materialien und Methodik 9

2.1. Material 9

2.1.1. Verbrauchsmaterialien 9

2.1.2. Gerätschaften 10

$\begin{array}{ll}\text { 2.1.3. Software } & 10\end{array}$

2.1.4. Pharmaka 11

2.1.5. Chemikalien 11

2.2. Versuchsaufbau 11

2.3. Versuchstiere 12

$\begin{array}{ll}\text { 2.4. Vorbereitung } & 13\end{array}$

2.4.1. Fluoresceinisothiocyanat Dextran 13

$\begin{array}{ll}\text { 2.4.2. Fibrinogen } & 13\end{array}$

2.4.3. Urbason $®$ solubile 14

2.4.4. Verblindung 14

2.4.5. Narkose 14

2.4.6. Platzierung der Elektroden zur Hirnstammaudiometrie 15

2.5. Operative Schritte 16

$\begin{array}{ll}\text { 2.5.1. Venöser Zugang und Blutentnahme } & 16\end{array}$ 
2.5.2. Fensterung der Cochlea zur Intravitalmikroskopie

2.5.3. Messung des arteriellen Mitteldrucks (MAP)

2.6. Erhebung der Messparameter 20

2.6.1. Hörschwellenbestimmung mittels Hirnstammaudiometrie 20

2.6.2. Cochleärer Blutfluss (CBF) 23

2.6.3. Blutdruckmessung 25

2.7. Statistische Auswertung $\quad 27$

3. Ergebnisse 29

3.1. Fibrinogenkonzentration 29

3.1.1. Plasmafibrinogenkonzentration der Placebo-Gruppe im Versuchsverlauf

3.1.2. Plasmafibrinogenkonzentration der Methylprednisolon$\begin{array}{ll}\text { Gruppe im Versuchsverlauf } & 30\end{array}$

3.1.3. Plasmafibrinogenkonzentration im Gruppenvergleich 31

3.2. Hörschwelle 32

3.2.1. Die Hörschwelle der Placebo-Gruppe im Versuchsverlauf 32

3.2.2. Die Hörschwelle der Methylprednisolon-Gruppe im Versuchsverlauf

3.2.3. Die Hörschwelle im Gruppenvergleich 34

3.3. Cochleärer Blutfluss 35

3.3.1. Die relative Änderung des cochleären Blutflusses der PlaceboGruppe im Versuchsverlauf

3.3.2. Die relative Änderung des cochleären Blutflusses der Methylprednisolon-Gruppe im Versuchsverlauf

3.3.3. Die relative Änderung des cochleären Blutflusses im Gruppenvergleich

3.4. Arterieller Mitteldruck

3.4.1. Der arterielle Mitteldruck der Placebo-Gruppe im Versuchsverlauf 38

3.4.2. Der arterielle Mitteldruck der Methylprednisolon-Gruppe im Versuchsverlauf

4. Diskussion

4.1. Das Hörvermögen in Abhängigkeit vom cochleären Blutfluss

4.2. Fibrinogen als Einflussfaktor bei der Entstehung eines akuten Hörverlusts 
Inhaltsverzeichnis

4.4. Stärken, Limitierungen und Ausblick $\quad 47$

5. Zusammenfassung 49

5.1. Deutsch 49

5.2. English 50

6. Literaturverzeichnis $\quad 51$ 


\section{Abbildungsverzeichnis}

Abbildung 1: $\quad$ Cochleärer Blutfluss und die arteriellen Endäste

Abbildung 2: $\quad$ Zeitliche Abfolge der Parameterbestimmung und des Injektionsprotokolls

Abbildung 3:

Abschluss der Versuchsvorbereitung

Abbildung 4:

Cochlea bei 8-facher Vergrößerung

Abbildung 5:

Cochlea bei 12-facher Vergrößerung

Abbildung 6:

Samba-Sonde zum Erheben des mittleren arteriellen Drucks 20

Abbildung 7:

Hirnstammaudiometrie

Abbildung 8:

Bildausschnitt während Fluoreszenz-Stereomikroskopie

Abbildung 9:

Videoausschnitt der Leica Application Suite Advanced

Flourescence Software

Abbildung 10:

Samba-Sondenmesskopf

Abbildung 11: $\quad$ Verlaufsmessung des mittleren arteriellen Blutdrucks

Abbildung 12: $\quad$ Plasmafibrinogenkonzentration in $\mathrm{mg} / \mathrm{dl}$ im Blut der Placebo-Gruppe zu den sechs Messzeitpunkten

Abbildung 13: $\quad$ Plasmafibrinogenkonzentration in mg/dl im Blut der Methylprednisolon-Gruppe zu den sechs Messzeitpunkten 31

Abbildung 14: $\quad$ Hörschwellenbestimmung der Placebo-Gruppe in dB zu den sechs Messzeitpunkten

Abbildung 15: $\quad$ Hörschwellenbestimmung der Methylprednisolon-Gruppe in $\mathrm{dB}$ zu den sechs Messzeitpunkten

Abbildung 16: $\quad$ Relative Änderung des cochleären Blutflusses der Placebo-Gruppe zu den sechs Messzeitpunkten

Abbildung 17: $\quad$ Relative Änderung des cochleären Blutflusses der Methylprednisolon-Gruppe zu den sechs Messzeitpunkten 


\section{Abkürzungsverzeichnis}

ATP Adenosintriphosphat

BERA Hörschwellenaudiometrie (brainstem evoked response audiometry)

CBF $\quad$ Erythrozytenfließgeschwindigkeit (cochlear blood flow)

CRP C-reaktives Protein

EEG Elektroenzephalographie

FITC Fluoresceinisothiocyanat (FITC) Dextran

HS Hörschwelle

KG Körpergewicht

MAP mittlerer arterieller Blutdruck (mean arterial pressure)

MRT Magnetresonanztomographie

$\mathrm{NaCl} \quad$ 0,9\%ige Lösung von Natriumchlorid in Wasser

PFK Plasmafibrinogenkonzentration

SSNHL Hörsturz (sudden sensorineural hearing loss)

TNF- $\alpha \quad$ Tumornekrosefaktor-alpha 


\section{Einleitung}

\subsection{Vorstellung der Arbeit}

Ziel der vorliegenden Arbeit war es, die Wirksamkeit der Gabe von Methylprednisolon zur Behandlung eines durch Hyperfibrinogenämie induzierten akuten Hörverlusts placebokontrolliert und verblindet in vivo zu untersuchen. Zur Verfügung stand ein Tiermodell, das an Dunkin-Hartley-Meerschweinchen die simultane Messung von Hörschwelle sowie Parametern der Mikrozirkulation nebst Applikation von Wirkstoffen erlaubt. Um eine vaskulär bedingte Hörminderung zu induzieren, wurde den Versuchstieren Fibrinogen injiziert. Eine Versuchsgruppe wurde daraufhin mit dem künstlichen Glucocorticoid Methylprednisolon behandelt. Die Kontrollgruppe erhielt physiologische Kochsalzlösung als Placebo.

Es wurden folgende Parameter bestimmt:

- Die Hörschwelle mittels Hirnstammaudiometrie

- Die Plasmafibrinogenkonzentration

- Der cochleäre Blutfluss mittels Intravitalmikroskopie

- Der mittlere arterielle Blutdruck

Zunächst wurden die Basisparameter bestimmt, bevor mittels Fibrinogeninjektion ein akuter Hörverlust induziert wurde. Im Verlauf wurden vor und nach Infusion der Prüfsubstanzen alle Messungen der Parameter in einem zeitlichen Abstand von 30 Minuten wiederholt. Der Versuch endete mit der sechsten Erhebung 120 Minuten nach Gabe der Prüfsubstanzen.

\subsection{Der Hörsturz}

Der Hörsturz (akuter idiopathischer sensorineuraler Hörverlust, sudden sensorineural hearing loss) ist definiert als „eine ohne erkennbare Ursache plötzlich auftretende, in der Regel einseitige Schallempfindungsschwerhörigkeit cochleärer Genese von unterschiedlichem Schweregrad bis hin zur Ertaubung“ (Leitlinie Hörsturz 2014, S. 1). Einhergehend können Schwindelgefühle, Ohrgeräusche, Ohrdruck, Hyperakusis und/oder Diplakusis als Symptome beobachtet werden. Untersuchungen zur Häufigkeit eines Hörsturzes ergaben Inzidenzen von 10,7/100.00 Personen (Byl 1977) bis hin zu 160-400 Neuerkrankungen pro 100.000 Einwoh- 
ner pro Jahr in Deutschland (Klemm et al. 2009; Olzowy et al. 2005). Bei derart hoher Inzidenz ist der Hörsturz eine regelmäßig vorkommende Erkrankung auf dem Gebiet der Hals-Nasen-Ohrenheilkunde.

Dabei ist die Wahrscheinlichkeit, dass lediglich ein Ohr betroffen ist, weitaus höher als ein beidseitiges Auftreten der Erkrankung. Männer und Frauen erkranken in etwa gleich häufig (Michel 1994), wobei die Erkrankung am häufigsten um das 50. Lebensjahr auftritt (Hallberg 1956; Mattox und Simmons 1977).

\subsubsection{Pathomechanismen}

Bis heute ist eine allgemeingültige Ätiologie und Pathogenese weitgehend unbekannt. Vielmehr stehen verschiedene Pathomechanismen im Verdacht, zur Manifestation des Krankheitsbildes des akuten idiopathischen sensorineuralen Hörverlusts beizutragen. Dabei reichen die Theorien der Pathogenese des Hörsturzes von Infektionen über autoimmunologische Ursachen bis hin zu Störungen der Blutzirkulation, wobei insbesondere die Beeinträchtigung der Mikrozirkulation im Innenohr als entscheidender Faktor bei der Entstehung des Krankheitsbildes diskutiert wird.

\subsubsection{Durchblutungsstörung}

In der Literatur werden verschiedene Theorien diskutiert, die in den meisten Fällen von rheologischen und vaskulären Problemen ausgehen. Mögliche Ursachen wären eine plötzliche Minderdurchblutung in der A. labyrinthi oder A. cochlearis, bedingt durch eine Embolie, Thrombose, Blutung oder einen Gefäßspasmus (Hilger 1952; Jaffe 1970). Da das gesamte Corti-Organ von der A. cochlearis als funktioneller Endarterie versorgt wird, liegt die Vermutung nahe, dass es bei einer etwaigen Durchblutungsstörung in diesem Abschnitt des Gefäßes zu einem plötzlichen Hörverlust kommen kann (Abbildung 1). In diesem Kontext wird der Hörsturz auch als Folge einer Veränderung der Blut- und Plasmaviskosität bzw. einer damit einhergehenden Veränderung der Blutflussgeschwindigkeit diskutiert (Klemm et al. 1983). 


\section{Cochleäre Mikrozirkulation}

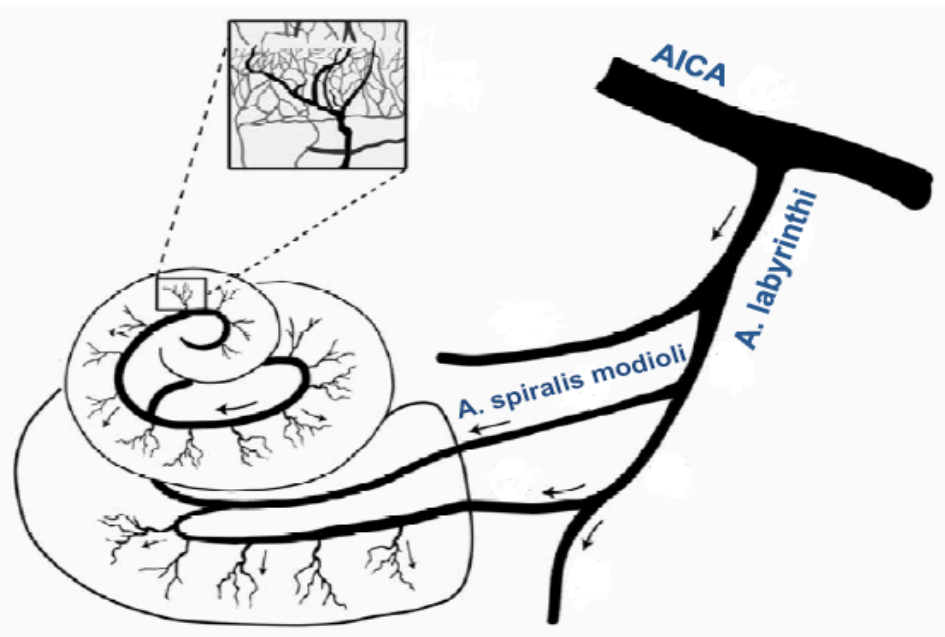

\section{Abbildung 1: Cochleärer Blutfluss und die arteriellen Endäste}

Schematische Darstellung der Blutversorgung des Innenohres ausgehend von der A. cerebelli anterior inferior (AICA) über die A. labyrinthi in die A. spiralis modioli in die A. cochlearis und ihre sich verzweigenden Endäste (modifiziert nach Nakashima et al. 2003; Die Verwendung erfolgt mit freundlicher Genehmigung des Elsevier Verlages)

Einen entscheidenden Einflussfaktor auf die Viskosität stellt das Protein Fibrinogen dar. Mit seinem spezifischen Gewicht von 340 kDa zählt Fibrinogen zu den großen Plasma-Glykoproteinen des menschlichen Körpers und wird in der Leber gebildet. Als Gerinnungsfaktor I und Akute-Phase-Protein ist das Molekül eng vergesellschaftet mit Wundheilungs- und Entzündungsreaktionen im Körper. Es ist maßgeblich an den rheologischen Eigenschaften des Blutflusses und der Plättchenaggregation bei der Blutgerinnung beteiligt. Der Normbereich wird in der Labordiagnostik der Universitätsmedizin Göttingen zwischen 200 - 393 mg/dl aufgeführt.

Ein Zusammenhang zwischen erhöhten Plasmafibrinogenkonzentrationen und bestimmten kardiovaskulären Erkrankungen wie dem akuten Myokartinfarkt oder dem Apoplex wurde bereits 1995 erwogen (Lip 1995). 2002 erkannte die Arbeitsgruppe um Markus Suckfüll eine Hyperfibrinogenämie als Risikofaktor für den 
Hörsturz. Es fiel auf, dass die Plasmafibrinogenkonzentrationen der HörsturzPatienten signifikant höher lagen als die einer Kontrollgruppe. Auch die Parameter Erythrozytenaggregation und Plasmaviskosität wurden in der Gruppe der Patienten mit plötzlichem Hörverlust signifikant erhöht gemessen (Suckfüll und Hearing Loss Study Group 2002).

Im Umkehrschluss wurde gezeigt, dass Patienten mit erhöhten Plasmafibrinogenkonzentrationen nach erlittenem Hörsturz von einer H.E.L.P-Apherese (Heparininduzierte extrakorporale LDL-Präzipitation) im Sinne einer Hörverbesserung profitieren (Suckfüll und Hearing Loss Study Group 2002; Bianchin et al. 2010).

In vivo zeigten Ihler et al. Anhand eines Tiermodells einen direkten Zusammenhang zwischen Plasmafibrinogenkonzentration, der Blutflussgeschwindigkeit in der Stria vascularis und dem Hörvermögen (Ihler et al. 2012). Dabei zeigte sich, dass sich das Hörvermögen der Tiere durch eine zuvor erzeugte Hyperfibrinogenämie signifikant verschlechtert und dass sich die Geschwindigkeit des cochleären Blutflusses antiproportional zum Anstieg der Plasmafibrinogenkonzentration verhielt.

\subsubsection{Infektion}

Des Weiteren werden Infektionen und damit einhergehende zelluläre Regulationsstörungen mit dem Krankheitsbild des Hörsturzes in Zusammenhang gebracht. In Verdacht stehen laut Leitlinie der deutschen Gesellschaft für Hals-Nasen-OhrenHeilkunde unter anderem Adenoviren, Mumpsviren und Herpes-Zoster-Viren (Leitlinie Hörsturz 2014).

Dieser Zusammenhang wird in der Literatur jedoch kontrovers diskutiert. So beschrieben etwa Veltri et al. einen Zusammenhang zwischen Masern, Herpes simplex, Influenza- und Zytomegalie Viren mit dem Hörsturz (Veltri et al. 1981) und auch andere Autoren erkannten einen Zusammenhang zwischen Virusinfektion und dem Krankheitsbild Hörsturz (Byl 1984). Pitkeränta et al. wie auch Gross et al. sehen hingegen keinen Bezug zwischen Virusbefall und einem Hörsturz (Pitkäranta und Julkunen 1998a; Gross et al. 2007). 


\subsection{Diagnostik des Hörsturzes}

Die Diagnose Hörsturz ist eine Ausschlussdiagnose und bedarf einer genauen Untersuchung des Patienten. Während der gesamten Untersuchung ist der Hörsturz immer als ein Symptom zu betrachten.

Die Diagnostik setzt sich zusammen aus einer notwendigen Diagnostik und verschiedener Zusatzdiagnostiken, die in Einzelfällen angewendet werden, um vermutete Ursachen zu belegen. Dabei gehört zu einer jeden Untersuchung eingangs die Anamnese des Patienten, um eine medikamentöse Ursache der plötzlichen Hörminderung auszuschließen. Insbesondere Medikamente wie Aminoglykoside und Zytostatika werden aufgrund ihrer Ototoxizität in Bezug zu einem akuten Hörverlust gesetzt (Landier 2016). Auch eine eingehende klinische Untersuchung mit obligater Blutdruckkontrolle und Ohrmikroskopie ist indiziert, um Differenzialdiagnosen wie einen Zeruminalpfropf oder einen Mittelohrerguß sowie Hypotonien auszuschließen. Um zwischen einer Schallleitungsschwerhörigkeit und einer Schallempfindungsschwerhörigkeit $\mathrm{zu}$ unterscheiden, wird eine orientierende Hörprüfung mittels Weber und Rinne Test durchgeführt. Hinzu kommt zudem eine Tonaudiometrie. Anhand dieser werden frequenzspezifisch die Lautstärken ermittelt, die gerade noch ein Hörempfinden hervorrufen. Dabei wird sowohl die notwendige Lautstärke für die Knochenleitung als auch für die Luftleitung betrachtet. Mittels der Werte für die Schallleitung über den Schädelknochen lassen sich Rückschlüsse über die Funktionsfähigkeit des Innenohres ziehen, die Luftleitung des Schalls gibt zudem Aufschluss über die Funktionsfähigkeit des Mittelohres. Eine Vestibularisprüfung mittels Frenzel-Brille und thermischer Prüfung ist ebenfalls bei der Verdachtsdiagnose Hörsturz indiziert. Zuletzt muss eine Tympanometrie erstellt werden. Diese misst die akustische Impedanz des Trommelfells. Während eines künstlich erzeugten Unter- sowie Überdrucks im äußeren Gehörgang wird die Schwingungsfähigkeit des Schallleitungsapparates untersucht. Mit ihr können unter anderem Hinweise auf eine Tubenventilationsstörung erlangt werden.

Zur Absicherung der Verdachtsdiagnose können weiterführende Untersuchungen wie Hirnstammaudiometrie, Stapediusreflexmessung und Kernspinntomographie zum Ausschluss einer retrocochleären Genese wie beispielsweise eines Kleinhirnbrückenwinkeltumors von großem Nutzen sein. 


\subsection{Therapie des Hörsturzes mit Glukokortikoiden}

Da die Pathogenese des Hörsturzes bislang nicht abschließend verstanden ist, herrscht auch heute noch keine allgemeingültige Einigkeit über einen kausalen Therapieansatz zur Behandlung des akuten Hörverlusts. Die verschiedenen Behandlungsstrategien leiten sich von den Theorien zur Ätiologie des Hörsturzes ab. In Deutschland ist die systemische Applikation von Kortikosteroiden der aktuelle therapeutische Standard (Leitlinie Hörsturz 2014).

Die Therapie mit Kortikosteroiden basiert auf der Annahme inflammatorischer oder Immunsystem-modulierender Prozesse als pathogenetische Ursache des Hörsturzes. Ein therapeutischer Effekt könnte auf der antiinflammatorischen und antiödematösen Wirkung wie auch auf einer erhöhten Katecholamin-Empfindlichkeit mit konsekutiver cochleärer Blutflusssteigerung beruhen.

Die Anwesenheit von Glukokortikoidrezeptoren im vestibulocochlearen System des Menschen wurde erstmals durch Rarey und Curtis beschrieben (Rarey und Curtis 1996). Auch hierin kann der Ansatz, akute idiopathische Innenohrerkrankungen durch Glukokortikoidgabe zu behandeln, bekräftigt werden. In der vorliegenden Arbeit soll die Wirksamkeit einer Behandlung mit Glukokortikoiden in einem Tiermodell für einen vaskulär durch akute Hyperfibrinogenämie bedingten Hörverlust untersucht werden. In vorausgegangenen Untersuchungen wurde gezeigt, dass Fibrinogen die Synthese von proinflammatorischen Zytokinen wie z. B. Tumornekrosefaktor- $\alpha$ induziert (Jensen et al. 2007). Durch die Aktivierung der vaskulären Sphingosin-1-Phosphat-Kaskade reduziert Tumornekrosefaktor- $\alpha$ den cochleären Blutfluss (Scherer et al. 2010; Ihler et al. 2013). Aus diesem Grund sollten inflammatorische und mikrozirkulationsbeeinflussende Faktoren in der Entstehung eines Hörsturzes nicht notwendigerweise getrennt voneinander betrachtet werden, sondern vielmehr in einem Zusammenhang. Da verschiedene Krankheiten und Mechanismen, wie beispielsweise Infektionen, systemische Entzündungsreaktionen oder auch Autoimmunerkrankungen, zu einer Ausschüttung von Tumornekrosefaktor- $\alpha$ führen, könnte dies auch in Zusammenhang mit der Genese eines akuten Hörverlust stehen. 


\subsubsection{Kortikosteroidsynthese}

Kortikosteroide sind körpereigene Hormone. Die Adenohypophyse produziert das adrenokortikotrope Hormon ACTH. Dieses Peptidhormon ist maßgeblich für die Regulation der Nebennierenrindenfunktion verantwortlich. Seine Anwesenheit stimuliert die Produktion der Glukokortikoide sowie der Mineralokortikoide. Nach dem Durchlaufen von mehreren Vorstufen wird so aus dem produzierten Cortison das in der Leber aktivierte Cortisol. Auf diese Weise werden am Tag in etwa 8 - 25 mg Cortisol und etwa 0,15 mg Aldosteron synthetisiert, wobei die Synthese einer zirkadianen Rhytmik unterliegt. Dabei liegt das Maximum der Produktion in den frühen Morgenstunden, das Minimum während des Schlafens. Bei körperlichem sowie psychischem Stress kann die Produktion des Cortisols um ein Vielfaches ansteigen (Boudarene et al. 2002).

Hauptaufgabe des körpereigenen Costisols ist es, inflammatorische Prozesse des Körpers zu regulieren. Dabei bindet das Cortisol an spezielle Glukokortikoidrezeptoren oder auch an Mineralokortikoidrezeptoren.

Neben den körpereigenen Glukokortikoiden sind mittlerweile zahlreiche synthetisierte Formen entwickelt. Diese unterscheiden sich im Wesentlichen in ihrer antiinflammatorischen Potenz und der Wirksamkeit bei der $\mathrm{Na}^{+}$-Rückresorption. Die bekanntesten Formen sind Prednison und Prednisolon, Methylprednisolon, Triamcinolon, Betamethason sowie Dexamethason.

Prednison und Prednisolon haben die vierfache Wirkung im Vergleich mit dem körpereigenen Cortisol, wobei sie eine 0,8fache $\mathrm{Na}^{+}$-Rückresorption verzeichnen. Sie binden sowohl an die Glukokortikoid- als auch an die Mineralokortikoidrezeptoren.

Das Methylprednisolon und das Triamcinolon weisen die fünffache Cortisolwirkung auf, bei 0,5facher $\mathrm{Na}^{+}$-Rückresorption. Das Methylprednisolon bindet ebenfalls an beide Rezeptortypen, wohingegen das Triamcinolon lediglich am Glukokortikoidrezeptor bindet. Betamethason und Dexamethason weisen sogar die 25fache Cortisolwirkung auf. Auch diese beiden künstlich synthetisierten Proteine binden nur an den Glykokortikoidrezeptor.

Die Halbwertszeit der künstlich hergestellten Proteine übersteigt die des körpereigenen Cortisols. So liegt sie für Cortisol bei 8 - 12 Stunden. Prednison, Prednisolon, Methylprednisolon sowie Triamcinolon weisen eine Halbwertszeit von 12 - 36 
Stunden auf, Beta- sowie Dexametason 36 - 72 Stunden.

\subsection{Fragestellung}

Der Pathomechanismus des Hörsturzes ist noch nicht abschließend verstanden, auch existieren verschiedene Therapieansätze, deren Evidenzlage als nur unzureichend eingeordnet werden kann. Folglich sind weitere Untersuchungen erforderlich, um die Entstehung und Behandlung des Hörsturzes besser zu verstehen.

Dabei sind Untersuchungen an Patienten technische sowie ethische Grenzen gesetzt. An dieser Stelle ist die Untersuchung der Therapiestrategien des vaskulär bedingten Hörsturzes in vivo im Tiermodell eine Alternative. So kann mit Hilfe des Tiermodells nach Canis et al. 2010 simultan die cochleäre Mikrozirkulation sowie die Hörschwelle bestimmt werden. Darauf aufbauend konnten Ihler et al. 2012 einen Zusammenhang zwischen Hörverlust und der Plasmafibrinogenkonzentration aufzeigen, nachdem die Fibrinogeninjektion in diesem Tiermodell zu einer Erhöhung der Hörschwelle führte. Zudem scheint Fibrinogen die Synthese proinflammatorischen Zytokine wie beispielsweise Tumornekrosefaktor- $\alpha \mathrm{zu}$ induzieren (Jensen et al. 2007). Tumornekrosefaktor- $\alpha$ wiederum reduziert den cochleären Blutfluss über den Sphingosin-1-Phosphat-Signalweg (Scherer et al. 2010; Ihler et al. 2013), sodass inflammatorische und mikrozirkulationsbeeinflussende Ursachen eines Hörsturzes nicht notwendigerweise getrennt voneinander betrachtet werden sollten.

Auf Grundlage dessen untersuchte diese Arbeit die Wirksamkeit einer Glukokortikoidtherapie gegenüber einer Placebo-Therapie in einem Tiermodell für einen akuten vaskulär bedingten Hörverlust. Die Glukokortikoidtherapie ist der aktuelle therapeutische Standard (Leitlinie Hörsturz 2014). 


\section{Materialien und Methodik}

\section{Vorbemerkung}

Alle im Folgenden beschriebenen Experimente dieser Dissertationsarbeit wurden in der Klinik für Hals-Nasen-Ohrenheilkunde (Direktor: Prof. Dr. med. Dirk Beutner) der Medizinischen Fakultät der Georg-August-Universität Göttingen durchgeführt. Die Messung der Plasmafibrinogenkonzentration erfolgte in Zusammenarbeit mit dem Institut für Klinische Chemie der Universitätsmedizin Göttingen. Alle Experimente wurden gemäß den nationalen Bestimmungen durchgeführt und durch die zuständigen Aufsichtsbehörden genehmigt. Seit dem 16.11.2012 liegt die Erlaubnis der Tierschutzkommission der Universitätsmedizin Göttingen vor. Seit dem 25.01.2013 besteht die Erlaubnis für diese tierexperimentelle Arbeit durch die zuständige Landesbehörde, das Niedersächsische Landesamt für Verbraucherschutz und Lebensmittelsicherheit (LAVES, Oldenburg) unter der Lizenznummer 33.9-42502-04-12/1011.

\subsection{Material}

\subsubsection{Verbrauchsmaterialien}

Einmalhandschuhe

Eppendorfgefäße

Falconröhrchen $15 \mathrm{ml}$

Futtermittel ssniff Ms-H

Feindosierungsspritze Omnifix-F, $1 \mathrm{ml}$

Injektionsspritze $5 \mathrm{ml}, 10 \mathrm{ml}$

Monovetten Coagulation 9 NC 0,5 ml

Einmalskalpell (Disposable Scalpel No. 11; 15)

Nahtmaterial Vicryl 5-0.

Sterican Kanüle rosa: $18 G$ x 1,5“ 1,2 x 40 mm

Sterican Kanüle hellgelb: $20 \mathrm{G}$ x 1“ 0,9 x 25 mm

Sterican Kanüle lila: $24 \mathrm{G}$ x 1“ 0,55 x 25 mm
Meditrade, Kiefersfelden

Eppendorf AG, Hamburg

Corning, NY USA

ssniff Spezialdiäten GmbH Soest

B. Braun, Melsungen

B. Braun, Melsungen

Sarstedt, Nümbrecht

Feather Safety Razor CO., Japan

Ethicon, Norderstedt

B. Braun, Melsungen

B. Braun, Melsungen

B. Braun, Melsungen 
Leukosilk Klebeband

Polypropylenkatheter ID 0,58 $\mathrm{mm}$ x OD 0,96 mm

Fuhrmann Vlieskompressen 5 x $5 \mathrm{~cm}$

Kettenbach Sugi REF 31603

Sarstedt Coagulation 9NC 0,5 ml Monovetten
BSN medical GmbH, Hamburg

Fisher Scientific, UK

Fuhrmann GmbH, Much

Kettenbach GmbH,

Eschenburg

Sarstedt, Nümbrecht

\subsubsection{Gerätschaften}

Chirurgische Schere BC061R

B. Braun, Melsungen

Carl Zeiss Operationsmikroskop OPMI

Carl Zeiss AG, Oberkochen

Mikroschere 24084

L. Klein AG, Schweiz

Mikronadelhalter 20-298-10

KLS Martin GmbH, Freiburg

Zentrifuge Heraeus PICO 17

Heraeus Holding GmbH, Hanau

Eppendorf Research $100 \mu$ l Pipette

Eppendorf, Hamburg

Bipolar Kauter Martin Elektrotom B50

Gebrüder Martin, Tuttlin-

Nadelhalter nach Mathieu $14 \mathrm{~cm}$

Blutdruckmessgerät gen

Seidel Medipool, Gauting Harvard Apparatus, Canada Samba: Preclin 420LP 1000CM 5CM STD

Fluoreszenz-Stereomikroskop LEICA M205 FA Leica, Wetzlar

Vortex Genie 2 Rüttelplatte

Scientific Industries Inc., NY, USA

\subsubsection{Software}

GSI Audera

Viasys HealthCareInc., Conshohocken, USA

SigmaPlot 2004 for Windows Version 12.0 Systat Software, Chicago, 
IL, USA

Adobe Illustrator

Adobe Systems Software, San Jose, CA, USA

StatSoft

\subsubsection{Pharmaka}

Ketamin $10 \% \quad$ Ketanest $^{\circledR}$ )

$\mathrm{NaCl} 0,9 \%$

Xylazin (Xylariem ${ }^{\circledR}$ i.v.)

Ultracain ${ }^{\circledR} 1 \%$-Suprarenin ${ }^{\circledR}$

Propanol $70 \%$

Urbason ${ }^{\circledR}$ solubile $16 \mathrm{mg}$
Medistar, Ascheberg

B. Braun, Melsungen

Ecuphar, Oostkamp Belgien

Sanofi, Frankfurt am Main

B. Braun, Melsungen

Sanofi, Frankfurt am Main

\subsubsection{Chemikalien}

Terg-a-zyme ${ }^{\circledR}$ enzyme detergent

Sigma-Aldrich, Missouri, USA

Fixanz für Fluoreszenzmikroskopie

Fluoresceinisothiocyanat Dextran Sigma, Deisenhofen

Molekulargewicht 500000-Conjugate

FITC:Glucose 1:100,

0,05-0,1 ml einer $5 \%$ Lösung in 0,9\% $\mathrm{NaCl}$

\subsection{Versuchsaufbau}

Es wurden zwei Versuchsgruppen mit einer Größe von jeweils fünf Versuchstieren untersucht. Es handelte sich bei den Versuchstieren um weibliche Dunkin-HartleyMeerschweine (Harlan Laboratories GmbH, An Venray, Niederlande; Charles River Laboratories, Sulzfeld, Deutschland). 
Nach Bestimmung der Basisparameter (Plasmafibrinogenkonzentration, Hörschwelle, cochleäre Blutflussgeschwindigkeit, mittlerer arterieller Blutdruck) wurde allen Versuchstieren Fibrinogen injiziert, um eine vaskulär bedingte Hörminderung zu induzieren. Nach erneuter Bestimmung der Parameter wurde eine Versuchsgruppe $(n=5)$ mit dem künstlichen Glukokortikoid Methylprednisolon (Urbason ${ }^{\circledR}$ solubile) behandelt $(5,3 \mathrm{mg} / \mathrm{kg}$ Körpergewicht [KG]). Eine Kontrollgruppe $(n=5)$ erhielt isotonische Kochsalzlösung als Placebo. Die Medikamentengabe erfolgte stets verblindet. Auch im Weiteren erfolgte zu den darauffolgenden Messzeitpunkten im Abstand von 30 Minuten die Bestimmung der oben genannten Parameter (Abbildung 2).

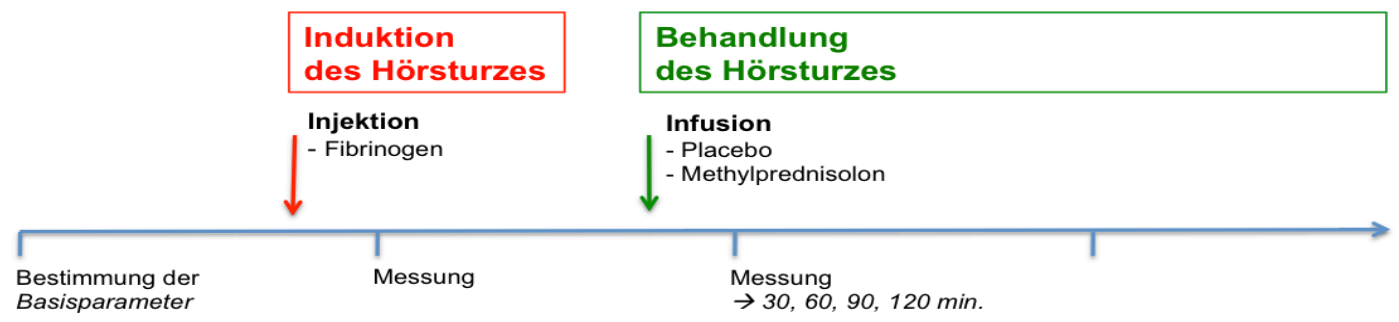

Abbildung 2: Zeitliche Abfolge der Parameterbestimmung und des Injektionsprotokolls

Die Versuchsreihe beginnt mit der Bestimmung der vier Basisparameter Plasmafibrinogenkonzentration, Hörschwelle, cochleäre Blutflussgeschwindigkeit, mittlerer arterieller Blutdruck. Im Anschluss erfolgt die Induktion des Hörsturzes durch einmalige Fibrinogengabe. Danach folgt eine erneute Bestimmung der Messparameter. Daraufhin wird durch Applikation der Prüfsubstanzen der Behandlungsversuch des induzierten Hörverlusts begonnen. Es folgen weitere Bestimmungen der Parameter bei 30, 60, 90 sowie 120 Minuten nach Induktion des Hörverlusts.

\subsection{Versuchstiere}

Bei den Versuchstieren handelte es sich um weibliche Dunkin-HartleyMeerschweinchen (Harlan Laboratories GmbH, An Venray, Niederlande; Charles River Laboratories, Sulzfeld, Deutschland). Die fachgerechte Tierhaltung war durch die Zentrale Tierexperimentelle Einrichtung der Universitätsmedizin Göttingen gewährleistet. Die Luftfeuchtigkeit lag bei 55 \% mit einer konstanten Temperatur 
zwischen 21 - $23{ }^{\circ} \mathrm{C}$. Das Gewicht der verwendeten Tiere lag zwischen $250 \mathrm{~g}$ und $470 \mathrm{~g}$.

Während der gesamten Unterbringung bekamen die Tiere Wasser ad libitum und spezielles Futtermittel der Firma ssniff Spezialdiäten GmbH. Der Tag/Nacht Rhythmus betrug $14 \mathrm{zu} 10$ Stunden. Nach Anlieferung der Tiere mussten diese nach Tierschutz-Versuchstierverordnung (TierSchVersV) 7 Tage ruhen, bevor sie als Versuchstiere verwendet werden konnten.

\subsection{Vorbereitung}

\subsubsection{Fluoresceinisothiocyanat Dextran}

Zur Darstellung des cochleären Blutflusses wurde der Plasmamarker Fluoresceinisothiocyanat (FITC) Dextran (Molekulargewicht 500000-Conjugate; FITC:Glucose 1:100) der Firma Sigma-Aldrich (Deisenhofen, Deutschland) verwendet. Das Anmischen erfolgte präoperativ. Dafür wurden 500 mg des Pulvers mit 10 ml 0,9 \% $\mathrm{NaCl}$ über 3 Minuten auf einer Vortex-Rüttelplatte in Lösung gebracht. 0,5 ml der 5 \%-Lösung wurden für den späteren Gebrauch in eine $1 \mathrm{ml}$ Spritze aufgezogen, mit Alufolie vor Licht geschützt und während der Dauer der Operation kühl gelagert.

\subsubsection{Fibrinogen}

Verwendet wurde humanes Plasmafibrinogen der Firma Sigma-Aldrich (Deisenhofen, Deutschland). Die Lagerung erfolgte in Pulverform bei 20 Grad Zimmertemperatur trocken und luftdicht. Präoperativ wurde das Fibrinogen gewichtsadaptiert zur Applikation vorbereitet. Hierzu wurden 0,33 mg/g Körpergewicht in $20 \mu \mathrm{l} / \mathrm{g}$ Körpergewicht 0,9 \% NaCl gelöst. Die Lösung erfolgte in einem 15 ml Falconröhrchen für fünf Minuten auf der Vortex-Rüttelplatte. Bis zum Zeitpunkt der Fibrinogengabe wurde das Gemisch bei Raumtemperatur gelagert. Die Applikation erfolgte durch einen Perfusor (20-ml-Spritze) mit einer Infusionsgeschwindigkeit von $1 \mathrm{ml} / \mathrm{min}$. 


\subsubsection{Urbason ${ }^{\circledR}$ solubile}

Als Prüfsubstanz zur Glukokortikoid-Behandlung wurde der Wirkstoff Methylprednisolon-21-hydrogensuccinat, Natriumsalz mit dem Handelsnamen Urbason ${ }^{\circledR}$ solubile der Firma Sanofi (Frankfurt am Main, Deutschland) gewählt. Eine Ampulle des Pulvers 20,92 mg Methylprednisolon-21-hydrogensuccinat, Natriumsalz gelöst im beiliegenden Lösungsmittel entsprach 15,78 mg Methylprednisolon. Präoperativ wurde die Lösung angemischt und gewichtsadaptiert in eine $1 \mathrm{ml}$ Spritze aufgezogen (5,3 mg/kg Körpergewicht [KG]).

\subsubsection{Verblindung}

Zur Verblindung wurden die Prüfsubstanzen durch einen Assistenten angemischt und kodiert gekennzeichnet. Für den Versuch wurde entweder eine Spritze mit Urbason ${ }^{\circledR}$ 5,3 mg/kg Körpergewicht [KG] oder äquivalent 2,5 ml/kg KG 0,9\% $\% \mathrm{NaCl}$ als Placebosubstanz durch den Assistenten bereitgelegt. In einer gesonderten Excel-Tabelle wurde durch den Assistenten jedem operierten Tier die jeweilige Prüfsubstanz mittels eines Buchstabencodes zugeteilt. Erst nach Beendigung aller Versuche und der Auswertung erfolgte die Entblindung.

\subsubsection{Narkose}

Die Narkose erfolgte durch eine abgewandelte Form der sogenannten Hellabrunner Mischung (50 \% Xylazin; 25 \% Ketamin 10 \%ig; 25 \% NaCl 0,9 \%ig). Die Dosierung erfolgte gewichtsadaptiert mit initialer Injektion von 85 mg/kg KG Ketamin und 8,5 mg/kg KG Xylazin. Perioperativ erhielten die Tiere alle $30 \mathrm{~min}$ eine Erhaltungsdosis von 42,5 mg/kg KG Ketamin und 4,25 mg/kg KG Xylazin. Zu Beginn wurde der linke Musculus quadriceps femoris zur Injektion gewählt, da auf der kontralateralen Seite die Sonde zur Bestimmung des arteriellen Mitteldrucks platziert wurde. Da im Verlauf mehrmalige Injektionen erforderlich waren, wurde auf Muskeln im Schulterbereich und auf der rechten Beinseite ausgewichen. 


\subsubsection{Platzierung der Elektroden zur Hirnstammaudiometrie}

Die Platzierung der Elektroden zur hirnstammaudiometrischen Messung erfolgte präoperativ nach Einleiten der Narkose. Die Einstichstellen der Nadelelektroden wurden mittels subkutaner Lokalanästhesie mit dem Wirkstoff Ultracain ${ }^{\circledR} 1$ \% Suprarenin ${ }^{\circledR}$ (Sanofi, Frankfurt am Main) an den entsprechenden Lokalisationen zwischen Nase und Augen am Vertex des Tieres, am Mastoid im Nackenbereich und am kaudalen Teil des Rückens anästhesiert. Im Anschluss wurden die Elektroden subkutan eingebracht. Hierzu wurde eine Hautfalte mit einer rosa Sterican Kanüle (1,2 x $40 \mathrm{~mm})$ durchstochen. Die Elektrode wurde in das Lumen der Kanüle eingeführt und diese samt Elektrode zurückgezogen um eine subkutane Platzierung zur Ableitung zu gewährleisten. Der Pluspol lag dabei zwischen Nasenbein und Augen, der Minuspol in Höhe des Processus mastoideus und die Erdung in Höhe zwischen den Lendenwirbeln und den Kreuzbeinwirbeln. Um eine Deplatzierung der Elektroden intraoperativ insbesondere während der Umlagerung des Tieres zu verhindern, wurden die freien Enden mit Hilfe eines Klebebandes am Fell und an der Haut des Tieres fixiert (Abbildung 3).

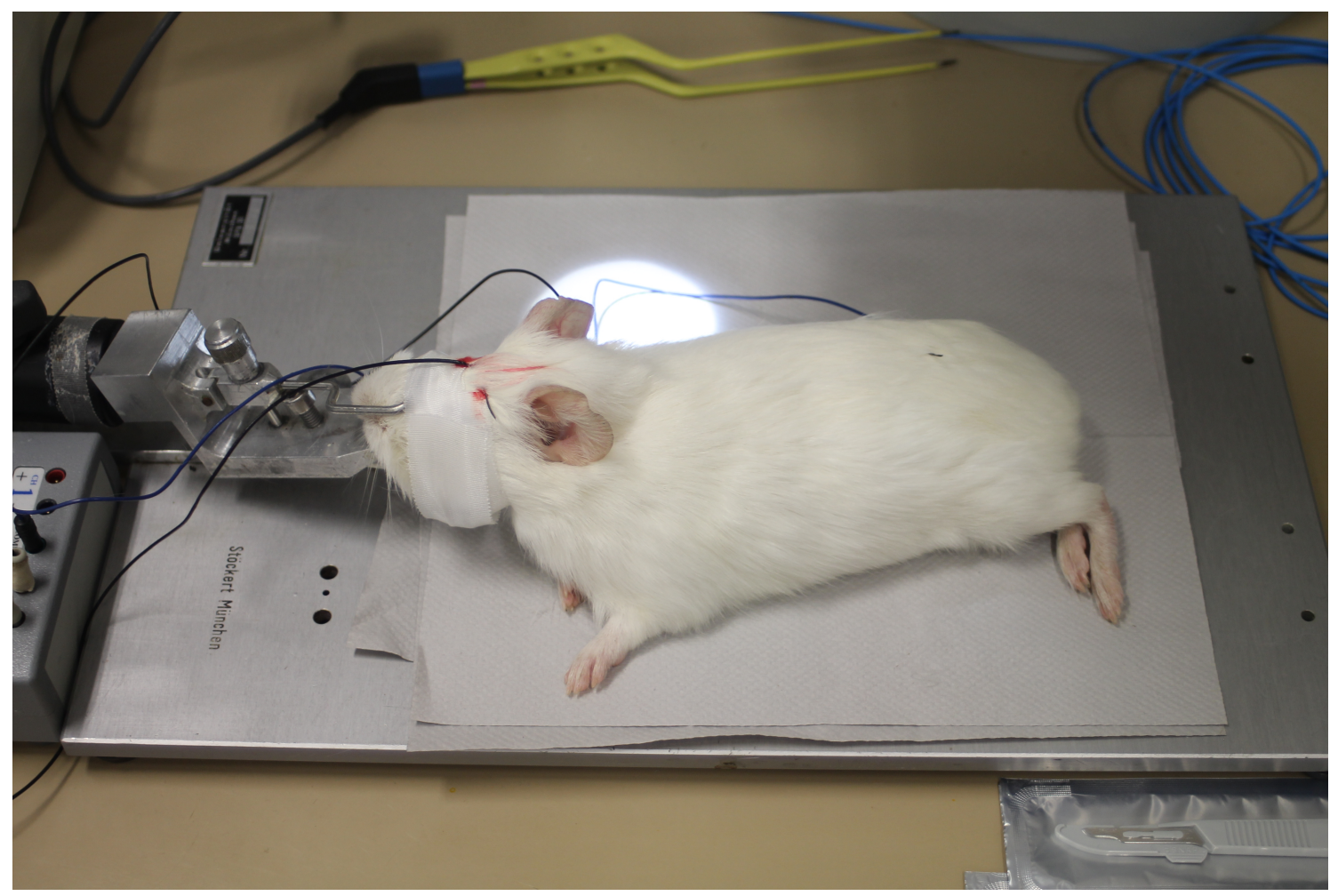

Abbildung 3: Abschluss der Versuchsvorbereitung

Das Tier wurde zu diesem Zeitpunkt in Narkose versetzt, im individuell gefertigten Fixateur eingespannt, danach lokal anästhesiert, um anschließend die drei Messelektroden zur Messung der Hirnstammaudiometrie an Stirn, Mastoid und Lendenwirbelsäule zu legen. 


\subsection{Operative Schritte}

Die Versuchstiere wurden in einem individuell gefertigten Fixateur (Abbildung 3) arretiert, um die Auswirkungen der Atemexkursion bei der späteren Intravitalmikroskopie so gering wie möglich zu halten. Alle operativen Schritte erfolgten unter optischer Vergrößerung mit Hilfe eines Carl Zeiss Operationsmikroskops (OPMI). Die Hautschnitte erfolgten mit einem Einmalskalpell der Klinge Nr. 15.

\subsubsection{Venöser Zugang und Blutentnahme}

Das Tier wurde in Rückenlage gelagert, die Haare der linken Körperseite wurden auf Höhe der Vena jugularis externa mechanisch mit Hilfe eines Einmalskalpells der Klinge Nr. 11 entfernt. Zur Lokalanästhesie wurden etwa 0,2 ml Ultracain ${ }^{\circledR} 1 \%$ Suprarenin ${ }^{\circledR}$ (Sanofi, Frankfurt am Main) injiziert. Im Anschluss wurde die linke Vena jugularis externa durch einen Hautschnitt und anschließend scharfes Durchtrennen des Platysma sowie stumpfer Präparation mittels chirurgischer Schere freigelegt. Es folgte das kraniale Abbinden zum Legen eines zentralvenösen Katheters. Nach kurzer Stauung wurde die Vene durch einen Schnitt mit der Mikroschere eröffnet. Als Ligatur eignete sich eine 5-0 Vicryl Naht. Ein Polypropylenkatheter wurde nach anterograd in die Vene eingebracht und etwa $4-6 \mathrm{~cm}$ in Richtung rechten Herzvorhof vorgeschoben.

Der Katheter diente dabei der Applikation von $\mathrm{NaCl}$ zur Kreislaufunterstützung, zur Applikation der Prüfsubstanzen und des Kontrastmittels sowie zur Blutentnahme.

Nach Legen des Katheters erfolgte unmittelbar die erste Blutentnahme zur Bestimmung des Basiswertes der Plasmafibrinogenkonzentration. Eine entsprechende Katheterposition zur raschen und blasenfreien Aspiration des venösen Blutes musste ermöglicht werden. Da es sich um einen nicht heparinisierten Polypropylenkatheter handelte, musste das Blut direkt nach Erreichen der Entnahmespritze in eine Sarstedt Monovetten überführt werden. Benötigt wurden 0,43 ml Blut, um die mit $0,07 \mathrm{ml}$ Citrat gefüllte Monovette bis zum Eichstrich bei 0,5 $\mathrm{ml} \mathrm{zu}$ befüllen. Direkt im Anschluss an die Blutentnahme wurde die befüllte Monovette vorsichtig geschwenkt um eine ausreichende Durchmischung des Blutes mit Citrat zu ge- 
währleisten. Danach wurde die Probe umgehend bei 2,2 G für 10 Minuten zentrifugiert. Nach Beenden des Vorganges wurde das Citratplasma abpipettiert und bei 4 ${ }^{\circ} \mathrm{C}$ im Kühlschrank zwischengelagert. Pipettiert wurde mit einer 100- $\mu$ l-Pipette. Durchschnittlich konnten 300 - $350 \mu$ l Citratplasma gewonnen werden.

Um die bestmögliche Position des Katheters während der intraoperativen Umlagerungen des Tieres zu jeder Zeit gewährleisten zu können, wurde dieser abschließend mit einer zusätzlichen Ligatur an der Vene nach caudal fixiert.

\subsubsection{Fensterung der Cochlea zur Intravitalmikroskopie}

Nach Legen des zentralvenösen Zuganges erfolgte die Umlagerung, um die Region des linken Ohres bestmöglich unter dem Operationsmikroskop darzustellen. Periaurikulär erfolgte eine großzügige Infiltration der Haut mit Lokalanästhetikum um operationsbedingte Schmerzen und Blutungen zu mindern. Das Ohr wurde eng an der Schädelkalotte abgesetzt, wobei die nah an der Schädelkalotte befindlichen Gefäße nach Möglichkeit geschont bzw. bei Eröffnung durch einen bipolaren Kauter embolisiert wurden. Der Arcus zygomaticus wurde dargestellt, im Weg befindliche Muskeln wurden reseziert. Im Anschluss erfolgte die mechanische Eröffnung der Schädelkalotte mittels eines Nadelhalters als Zangeninstrument zwischen Arcus zygomaticus und Porus acusticus externus. Das Trommelfell, der M. tensor tympani und die Gehörknöchelchen wurden entfernt, sodass die Cochlea durch eine seitliche Erweiterung des Zuganges dargestellt werden konnte (Abbildung 4). Bei freiem Blick auf die Cochlea wurde diese auf Höhe der mittleren Windung quadratisch, und maximal atraumatisch gefenstert. Ziel war es, die sich unter dem Knochen befindliche Stria vascularis maximal zu schonen, um die cochleären Gefäße, deren Blutfluss im weiteren Verlauf des Experiments untersucht werden sollte, nicht zu verletzen. Das in etwa quadratische Fenster sollte nach Möglichkeit eine Seitenlänge von $200 \mu \mathrm{m}$ aufweisen. Um einen Knochendeckel von der Cochlea abheben zu können, wurden zunächst mit einem Einmalskalpell der Größe Nr. 11 eine Sollbruchstellen in die knöcherne Hülle der Cochlea geritzt, um im Anschluss den Knochendeckel durch Abheben mittels Skalpellspitze oder einer Kanüle und durch Unterspülen mit 0,5 $\mathrm{ml} \mathrm{NaCl}$ von der Unterlage zu trennen und wegzuschwemmen (Abbildung 5). 


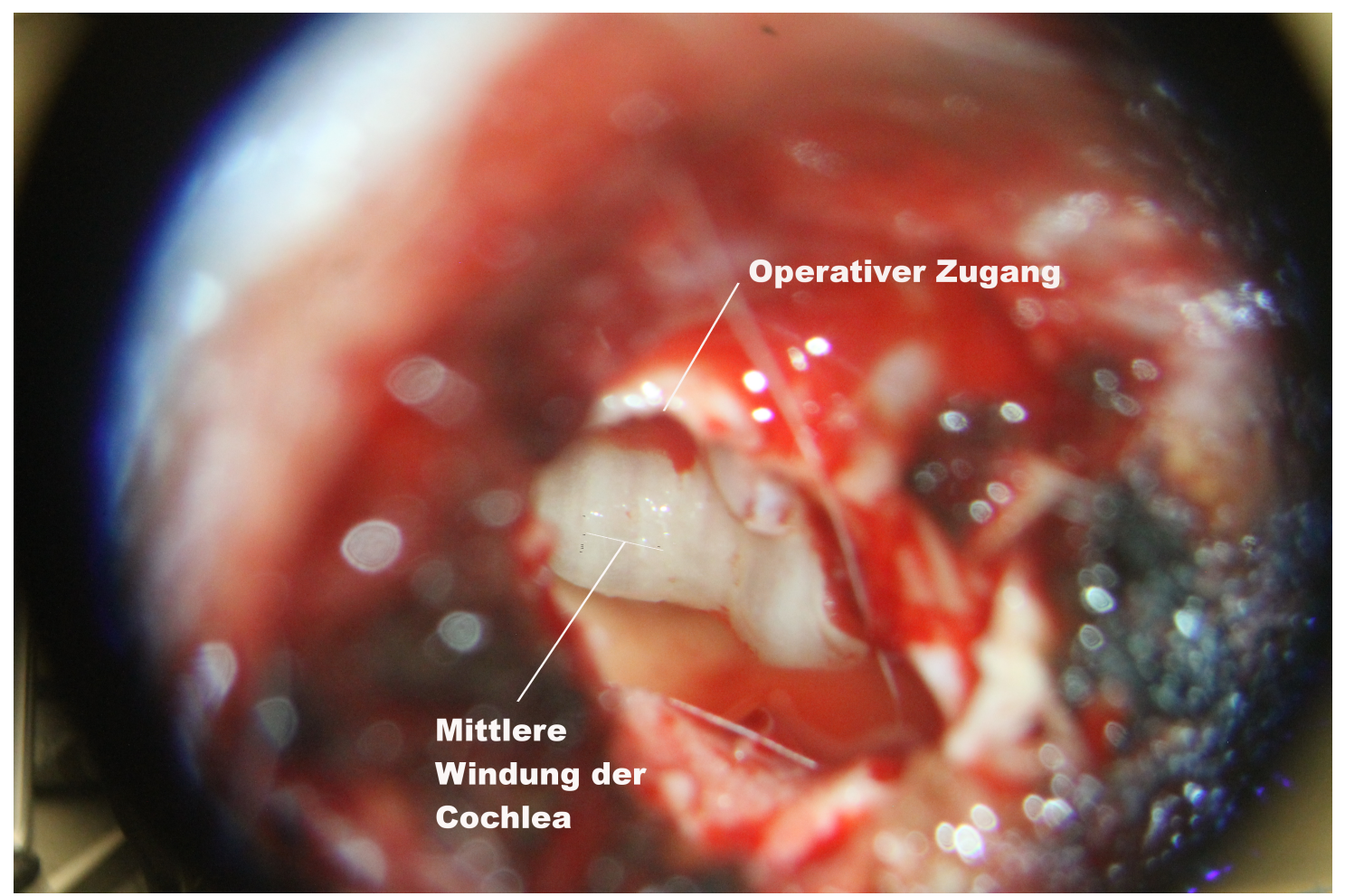

\section{Abbildung 4: Cochlea bei 8-facher Vergrößerung}

Darstellung der freipräparierten Cochlea in der Bulla nach Absetzen des Ohres und Entfernen der nach lateral begrenzenden Strukturen wie Haut, Schädelkalotte, Arcus zygomaticus, Gehörknöchelchen sowie des Trommelfells.

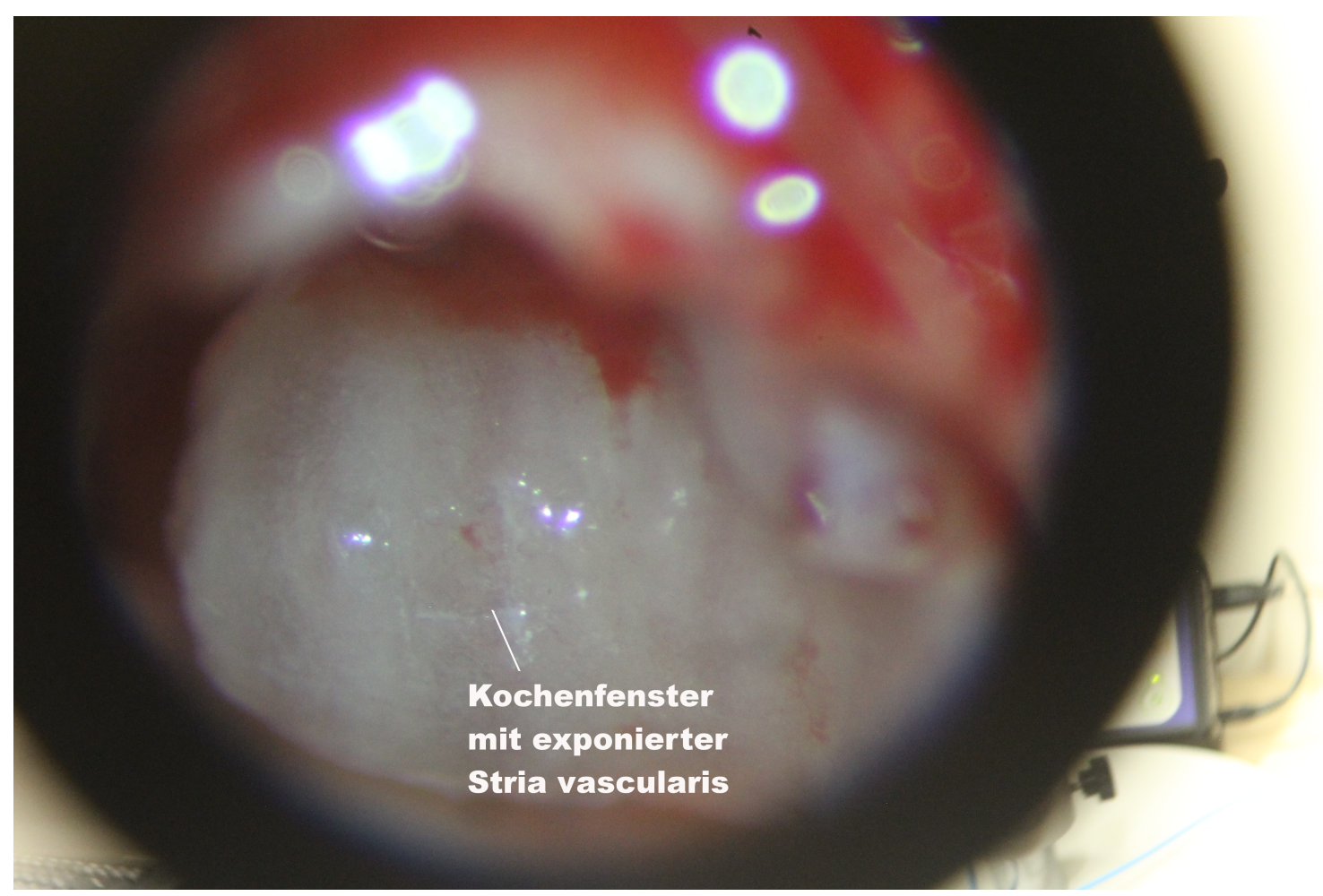

\section{Abbildung 5: Cochlea bei 12-facher Vergrößerung}

Im Bereich der mittleren Windung der Cochlea wird der Knochendeckel abgehoben und die darunter liegende Stria vascularis auf Unversehrtheit hin kontrolliert. 


\subsubsection{Messung des arteriellen Mitteldrucks (MAP)}

Nach Umlagern in Rückenlage wurde das Tier auf der rechten Innenseite des Beines rasiert und die Haut in Höhe der Arteria femoralis subkutan mit Lokalanästhetikum infiltriert. Nach erfolgtem Hautschnitt wurde die Arterie mittels stumpfer Präparation mit einer Operationsschere freigelegt. Die Adventitia wurde nach Möglichkeit vollständig entfernt. Um das Einführen der Blutdruck-Messsonde zu ermöglichen, wurde das Gefäß nach kaudal zur Stauung temporär ligiert. Um der natürlichen Vasokonstriktion der Arterie, die durch die Manipulation zusätzlich getriggert wurde, entgegenzuwirken, wurde das Gefäß vor der Inzision durch vorsichtiges Betupfen mit Propanol weitgestellt. Nach kranial wurde das Gefäß mit Hilfe eines mikrochirurgischen Nadelhalters temporär abgeklemmt, um unnötigen Blutverlust nach dem Eröffnen zu vermeiden. Auf diese Weise ergab sich ein etwa 6 mm langer Gefäßabschnitt, der mittig in horizontaler Richtung mit einer mikrochirurgischen Schere eröffnet wurde. Nach derartiger Eröffnung der A. femoralis wurde der Messkatheter eines Samba-Blutdruckmessgerätes für die Ermittlung der Herzfrequenz und des arteriellen Mitteldrucks (MAP) in die Arterie eingebracht und nach Lösen der Klemme nach retrograd bis in die A. iliaca vorgeschoben (Abbildung 6). 


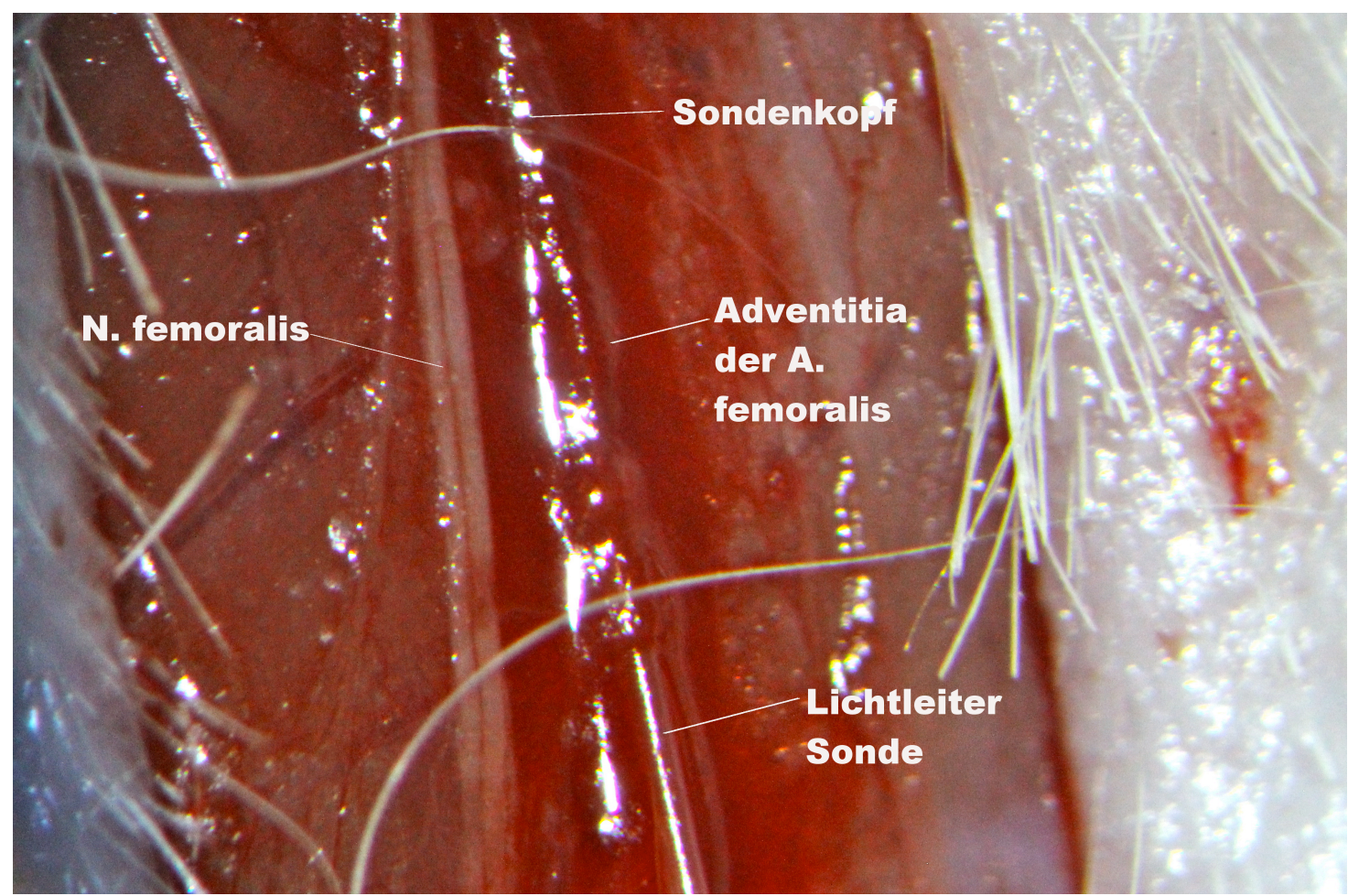

Abbildung 6: Samba-Sonde zum Erheben des mittleren arteriellen Drucks

Operationssitus bei eingebrachter Sonde zur Datenerhebung des arteriellen Mitteldrucks. Die Sonde wird nach Inzision der A. femoralis nach kranial in der Arterie vorgeschoben um während der weiteren Versuchsschritte kontinuierlich den Blutdruck als wichtigen Vitalparameter zu monitoren.

\subsection{Erhebung der Messparameter}

\subsubsection{Hörschwellenbestimmung mittels Hirnstammaudiometrie}

Die Hirnstammaudiometrie bzw. BERA (brainstem evoked response audiometry) ist eine Untersuchungsmethode zur objektiven Bestimmung des Hörvermögens. Es werden Antwortpotentiale auf akustische Reizung von einer subkutanen positiven Elektrode über dem Vertex und einer subkutanen negativen Elektrode am Mastoid abgeleitet. Die akustischen Potentiale werden durch Klicklaute über einen Ohrstöpsel auf der zur Intravitalmikroskopie kontralateralen Seite evoziert. Eine Referenzelektrode (Erdung) wird subkutan in Höhe der kaudalen Rückenmuskulatur gelegt, wie im Abschnitt präoperative Vorbereitung beschrieben. Um störende EEG-Ableitungen herauszufiltern, wurde ein Tiefpass-Filter bei $1500 \mathrm{~Hz}$ gesetzt. Dadurch wurde lediglich die Antwort des Hirnstammes auf die akustischen Reize abgeleitet. 
Der akustische Reiz bestand aus linearen 8-kH-Tönen (linearer Anstieg - Plateau linearer Abfall: 2-1-2) mit wechselnder Polarität bei einer Wiederholungsrate von 20,1 Hz. Zur Auswertung wurde die Welle III der Potentialableitung herangezogen. In 10 Dezibel Schritten, von $70 \mathrm{~dB}$ absteigend, wurde sich der Hörempfindungsschwelle bis zu 0 dB angenähert. Eine Latenz war absteigend in einer Rechtsverschiebung der Wellen zu erkennen und wurde bis zu einer Größe von 3,8 ms akzeptiert. Die Hörschwelle war erreicht, wenn die Amplitude der Welle III mindestens eine Höhe von $0,03-\mu \mathrm{V}$ besaß (Abbildung 7). Gemessen wurde die Hörschwelle des rechten Ohres, auf der kontralateralen Seite erfolgte zuvor die Darstellung der Stria vascularis zur Intravitalmikroskopie. Die Hörschwellenbestimmung erfolgte mit Hilfe des Programmes GSI Audera (Viasys HealthCareInc., Conshohocken, USA). 


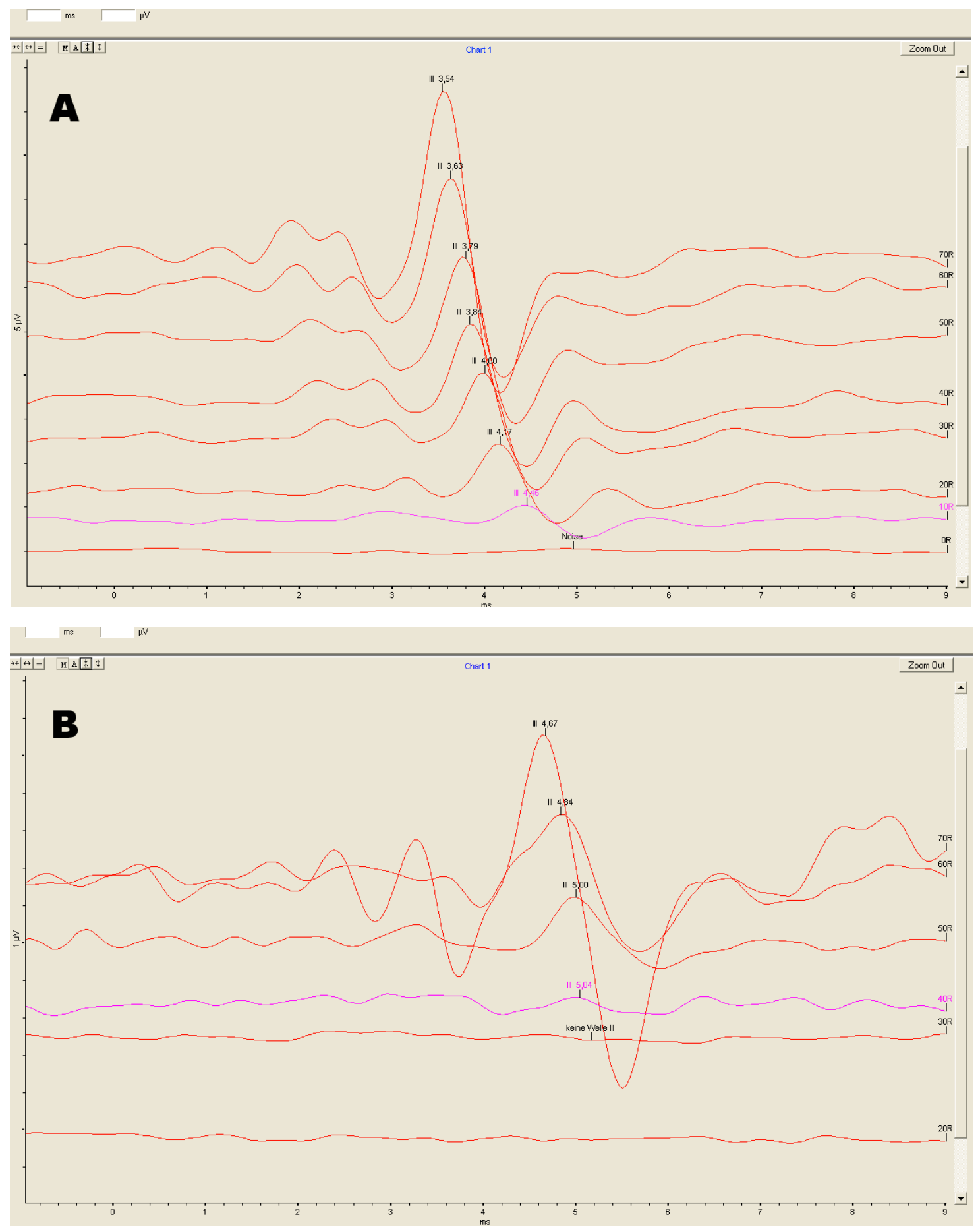

Abbildung 7 Hirnstammaudiometrie

Ableitung der hirnstammaudiometrischen Potentiale zum Zeitpunkt der Basisparameterbestimmung. Bei Betrachtung der dritten Welle lag die Hörschwelle bei $10 \mathrm{~dB}(\mathrm{~A})$.

Ableitung der hirnstammaudiometrischen Potentiale bei Parameterbestimmung 90 min. nach Fibrinogengabe. Bei Betrachtung der dritten Welle lag die Hörschwelle bei $40 \mathrm{~dB}(\mathrm{~B})$. 


\subsubsection{Cochleärer Blutfluss (CBF)}

Um die Fließgeschwindigkeit des Blutes in den cochleären Gefäßen zu einem bestimmten Zeitpunkt zu bestimmen wurde die Stria vascularis, wie in Abschnitt 2.5.2. beschrieben, exponiert. Um den Blutfluss im Fluoreszenz-Stereomikroskop sichtbar zu machen, wurde das Blutplasma durch den Plasmamarker Fluoresceinisothiocyanat (FITC) Dextran kontrastiert. 0,5 ml des FITC wurden hierzu intravenös über den zuvor gelegten Katheter appliziert. Über seine Isothiocyanatgruppe reagiert es mit den primären Aminresten der im Blut befindlichen Proteine. Durch seine selektive Bindung exponierte das Färbemittel die Proteine bei Betrachtung unter dem Fluoreszenz-Stereomikroskop. Das Floureszenzoptimum des FITC liegt bei einer Wellenlänge zwischen $492 \mathrm{~nm} / 518 \mathrm{~nm}$ (Sigma-Aldrich Website).

Unmittelbar nach Gabe des Reagenz wurde das Tier zur Intravitalmikroskopie unter dem Leica Stereomikroskop gelagert. Durch den Fixateur wurde die durch die Atemexkursion bedingte Bewegungsunschärfe während der Mikroskopie so gering wie möglich gehalten. Die mittlere Windung der Cochlea mit dem zuvor geschaffenen Knochenfenster wurde eingestellt. Die Gefäße der Stria vascularis wurden in zwölffacher Vergrößerung dargestellt.

Es musste sichergestellt sein, dass die Gefäße während der Präparation unverletzt geblieben waren und in einer ausreichenden Schärfe dargestellt werden können. Zwei Gefäße wurden für die Analyse ausgewählt, um an ihnen im Folgenden die Parameter der cochleären Mikrozirkulation zu ermitteln. Die beiden Gefäße mussten hierzu möglichst nah beieinander liegen um in einem Bildausschnitt von $500 \mathrm{x}$ $500 \mu \mathrm{m}$ darstellbar zu sein. Es wurde mit Hilfe der Leica Application Suite Advanced Flourescence Software ein 90-sekündiges Video mit 25 Bildern pro Sekunde aufgezeichnet. 


\section{Knochenfenster}

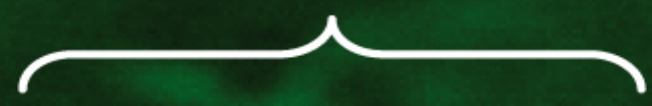

\section{Präkapillare}

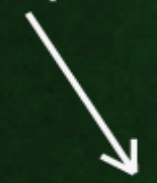

Stria vaskularis

Abbildung 8: Bildausschnitt während Fluoreszenz-Stereomikroskopie

Durch das Knochenfenster im Bereich der mittleren Windung der Cochlea ist nach FITC-Applikation die Stria vaskularis darstellbar.

In der Nachbearbeitung der Videos wurde für jedes Gefäß ein 7-sekündiges lineshift-Diagramm erstellt und an ihm die Erythrozytenfließgeschwindigkeit v ( $\mu \mathrm{m} / \mathrm{s})$ und der Gefäßdurchmesser d $(\mu \mathrm{m})$ an jeweils 3 unterschiedlichen Teilbereichen gemessen. Die Werte der beiden Gefäße sowie die der drei Messbereiche wurden gemittelt. Aus den derart ermittelten Werten wurde zur Bestimmung des cochleären Blutflusses q (pl/s) die Formel von Baker and Wayland angewandt (Baker und Wayland 1974):

$\mathrm{q}=(\mathrm{v} / 1.6) \times(\mathrm{d} / 2)^{2} \times \pi$ 


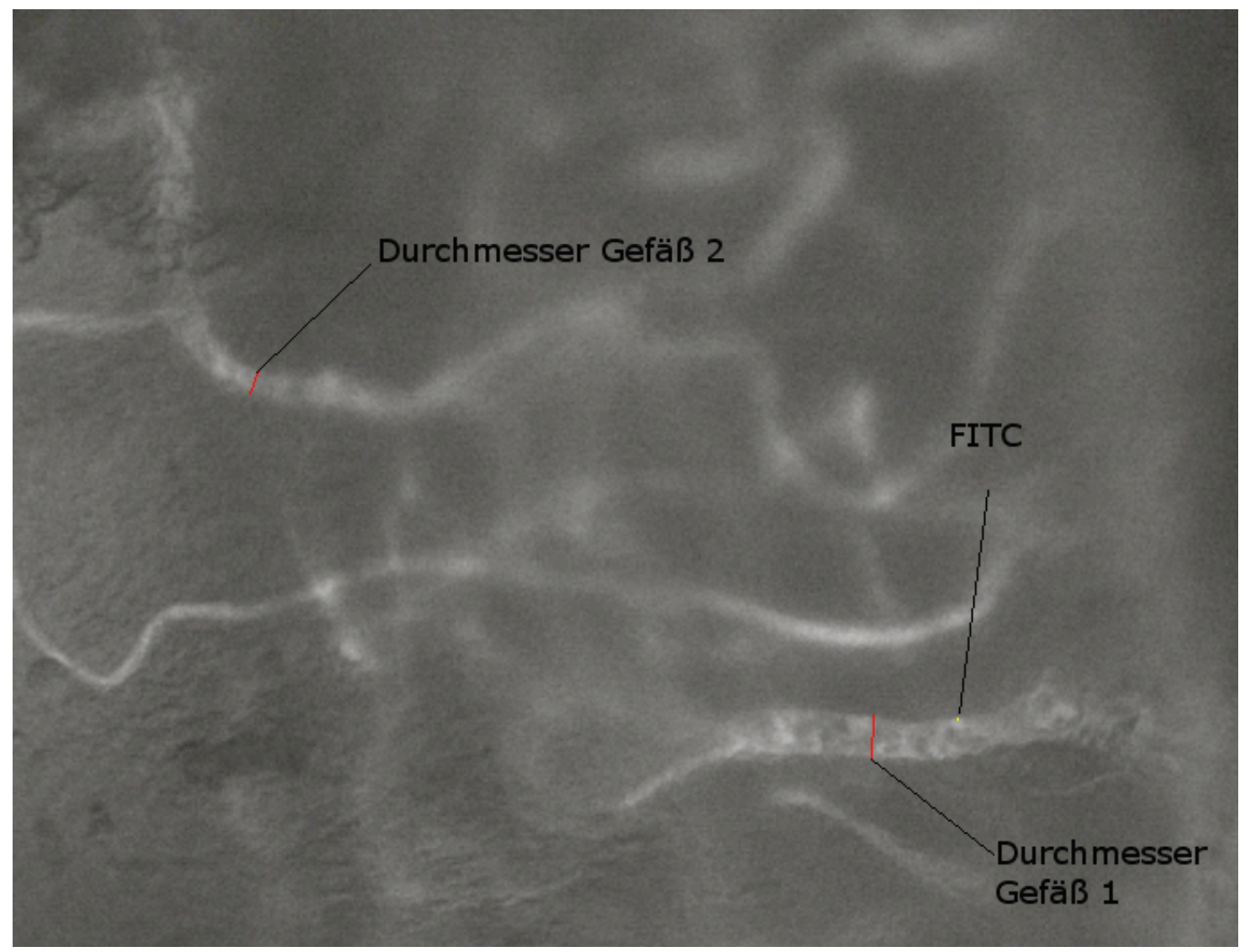

Abbildung 9: Videoausschnitt der Leica Application Suite Advanced Flourescence Software

Gefäßauswahl und Messung des Gefäßdurchmessers zur Bestimmung des cochleären Blutflusses im Bereich der Stria vaskularis.

\subsubsection{Blutdruckmessung}

Zur Kontrolle der Vitalparameter wurde der arterielle Mitteldruck während des gesamten Versuches erhoben. Hierzu wurde die A. femoralis freigelegt und der Messsondenkopf bis in die A. iliaca vorgeschoben. Um die Thrombogenität der Messsonde herabzusetzen, lagerte diese von Operationsbeginn bis zum Einbringen in die Arterie in einer Terg-a-Zyme Lösung der Firma Sigma-Aldrich. Die Proteasen-enthaltende Enzymlösung eignet sich zum Entfernen von Geweberückständen auf Medizinartikeln.

Die Größe des Messkopfes beträgt 0,36-0,42 mm im Durchmesser und ist durch ein 0,25 mm dickes optisches Fieberglas mit dem Kontrollpanel verbunden.

Trifft die Blutdruckwelle auf die Messmembran des Sensorkopfes, deformiert diese leicht und das Lichtsignal fließt verändert zurück in das Kontrollpanel. Dieses konvertiert das Signal in digitale Werte und wertet diese mittels der mitgelieferten Software aus. 

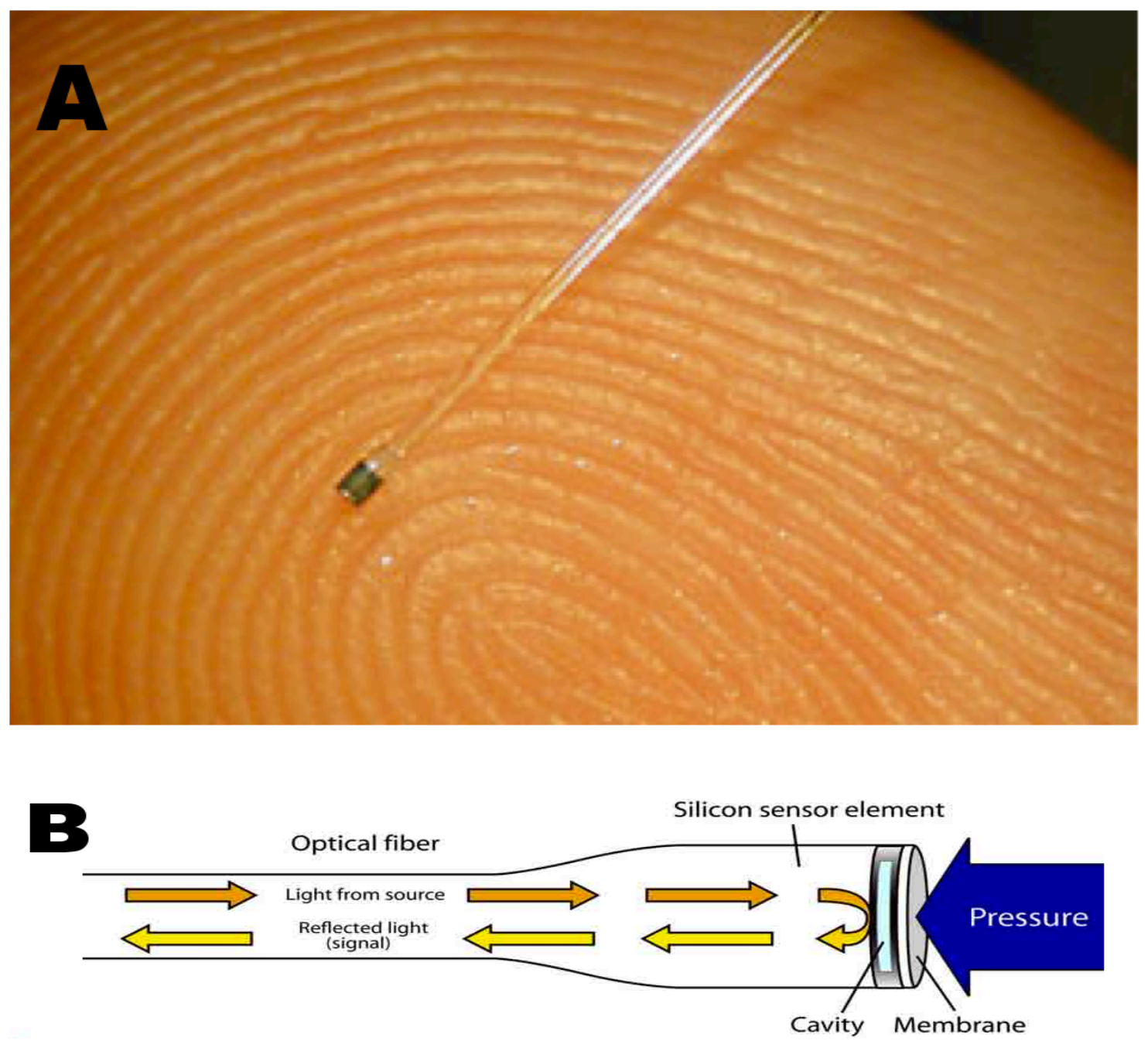

Abbildung 10: Samba-Sondenmesskopf

Maßstab der Größe des Sondenkopfes in Bezug auf eine menschliche Fingerbeere (A). Veranschaulichte Darstellung des Funktionsprinzips des Sensors (B) Quelle: www.sensorsmag.com, Mindedal, 2007. Die Verwendung erfolgt mit freundlicher Genehmigung des Questex Verlages.

Da während einer Verlaufsmessung nicht alle Blutdruckwerte zu jedem Zeitpunkt der Operation von Bedeutung für die Ergebnisse waren, wurden zum Zeitpunkt der Videoaufnahmen (Ereignis 1-blau), zum Zeitpunkt der Fibrinogengabe (Ereignis 2-rot) und zum Zeitpunkt der Medikamentengabe (Ereignis 3-grün) Markierungen gesetzt (Abbildung 11). Bei der Auswertung wurden um jedes Ereignis die vorangegangenen 150 Sekunden und die nachfolgenden 150 Sekunden, insgesamt also 300 Sekunden bzw. 5 Minuten um das Ereignis betrachtet. Diese Werte wurden gemittelt und in mmHg angegeben. 


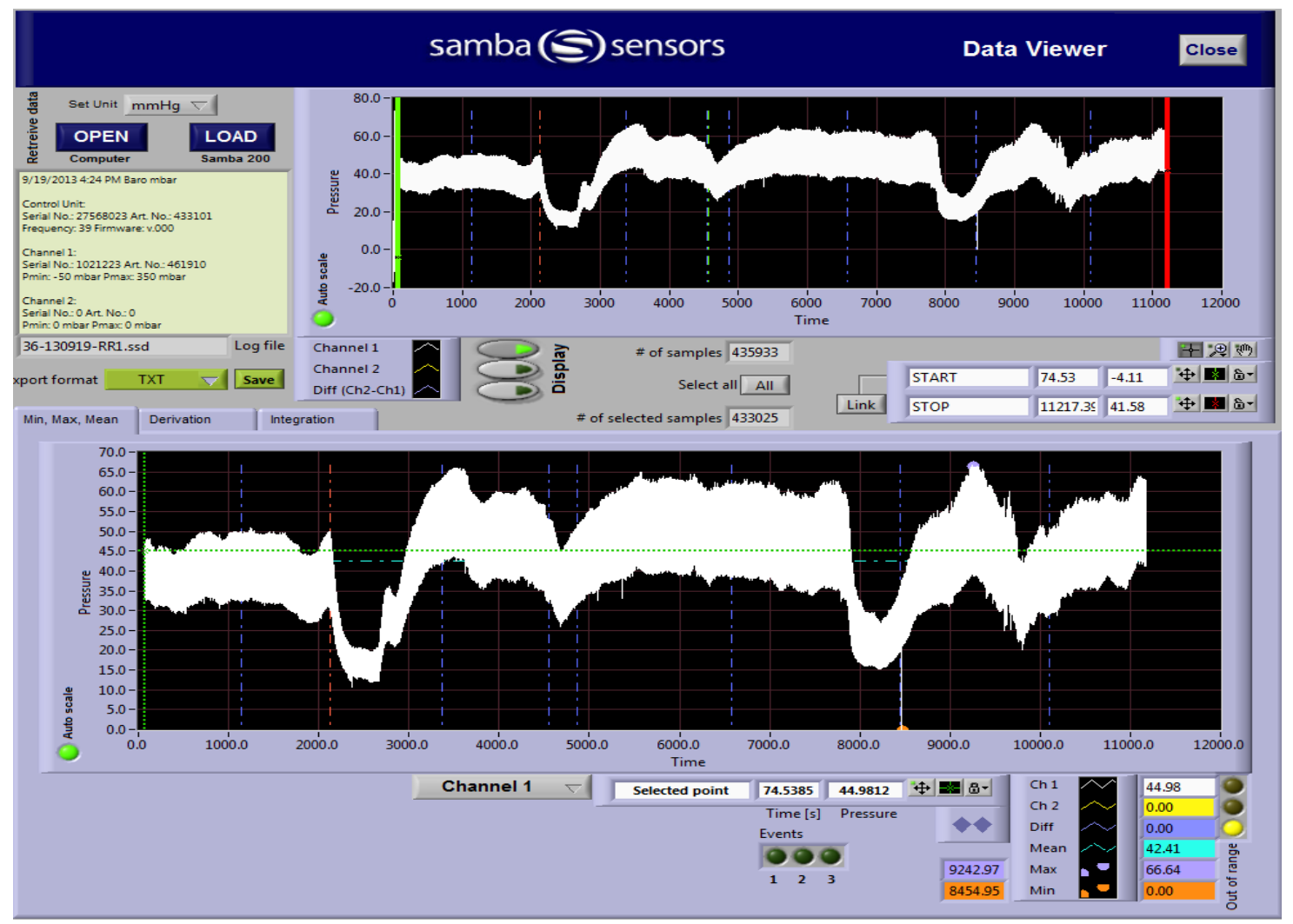

Abbildung 11: Verlaufsmessung des mittleren arteriellen Blutdrucks

Die blauen Markierungen geben die Zeitpunkte der Videoaufnahmen während des Experimentes wieder. In Rot gekennzeichnet wurde der Zeitpunkt der Videoaufnahme bei Fibrinogengabe. Die grüne Markierung gibt den Zeitpunkt der Videoaufnahme bei Medikamentengabe an.

\subsection{Statistische Auswertung}

Die im Rahmen dieser Dissertationsarbeit dargestellten Experimente und Ergebnisse sind Teil einer Versuchsreihe mit drei Versuchsgruppen. Die statistische Auswertung erfolgte für alle drei Versuchsgruppen mittels Two Way ANOVA für wiederholte Messungen. Die in der Arbeit berichteten Ergebnisse der statistischen Auswertung sind Teil des Gesamtergebnisses.

Die statistische Analyse erfolgte mit Hilfe des Programms SigmaPlot 2004 für Windows- Version 12.0 (Systat Software, Chicago, IL, USA). Die zweifache Varianzanalyse mit wiederholten Messungen (2way RM ANOVA) wurde verwendet, um die Werte zum Zeitpunkt nach der Injektion von Fibrinogen (Induktion des Hörverlusts) mit den basalen Werten und den Werten bei 30, 60, 90 und 120 Minuten nach der Infusion der Prüfsubstanzen zu vergleichen. Ebenso wurden die beiden Testgruppen (Methylprednisolon- vs. Placebo-Gruppe) zu einem bestimmten Zeitpunkt miteinander verglichen. Der Bonferroni-t-Test wurde durchgeführt um eine 
Aussage über die statistische Signifikanz der Unterschiede zu treffen. Die Daten sind als Mittelwerte mit Spannweite (R) \pm Standardabweichung angegeben. In allen durchgeführten Tests wurde ein P-Wert von $\alpha<0,05$ als statistisch signifikant angesehen.

Die Datensammlung erfolgte mit Hilfe von Microsoft Excel (Version Excel 2008, Microsoft Corporation, Redmond, USA). Grafiken wurden mit der Software Statistika (Version 12.7, StatSoft, Hamburg, Deutschland) erstellt und mittels Adobe Illustrator (Version CS 6, Adobe Systems Incorporated, San José, USA) stilistisch modifiziert. 


\section{Ergebnisse}

\subsection{Fibrinogenkonzentration}

\subsubsection{Plasmafibrinogenkonzentration der Placebo-Gruppe im Versuchsver-} lauf

Zum Zeitpunkt der Bestimmung der Basisparameter betrug die Plasmafibrinogenkonzentration (PFK) im Mittel 131,4 mg/dl (R = 110 - 166; \pm 21 ). Unmittelbar nach der gewichtsadaptierten Fibrinogengabe stieg diese signifikant um 260,4 \% auf einen Wert von im Mittel 473,6 mg/dl an ( $\mathrm{R}=345-567 ; \pm 85,3 ; \mathrm{p}<0,01) .30$ Minuten nach Applikation von Kochsalzlösung als Placebo blieb die PFK fast unverändert bei $468 \mathrm{mg} / \mathrm{dl}(\mathrm{R}=420-538 ; \pm 52,4)$. Bis zur Beendigung des Versuches kam es zu keiner signifikanten Änderung. 120 min nach Therapie mit Placebo wurden die letzten Werte mit 424,3 mg/dl gemessen ( $\mathrm{R}=378-466 ; \pm 62,2)$

Nach gewichtsabhängiger Fibrinogeninfusion (330 mg/kg KG) stieg die PFK also signifikant an und verblieb im Versuchsverlauf innerhalb der untersuchten 150 Minuten nach Fibrinogengabe auf einem ähnlichen Niveau. 


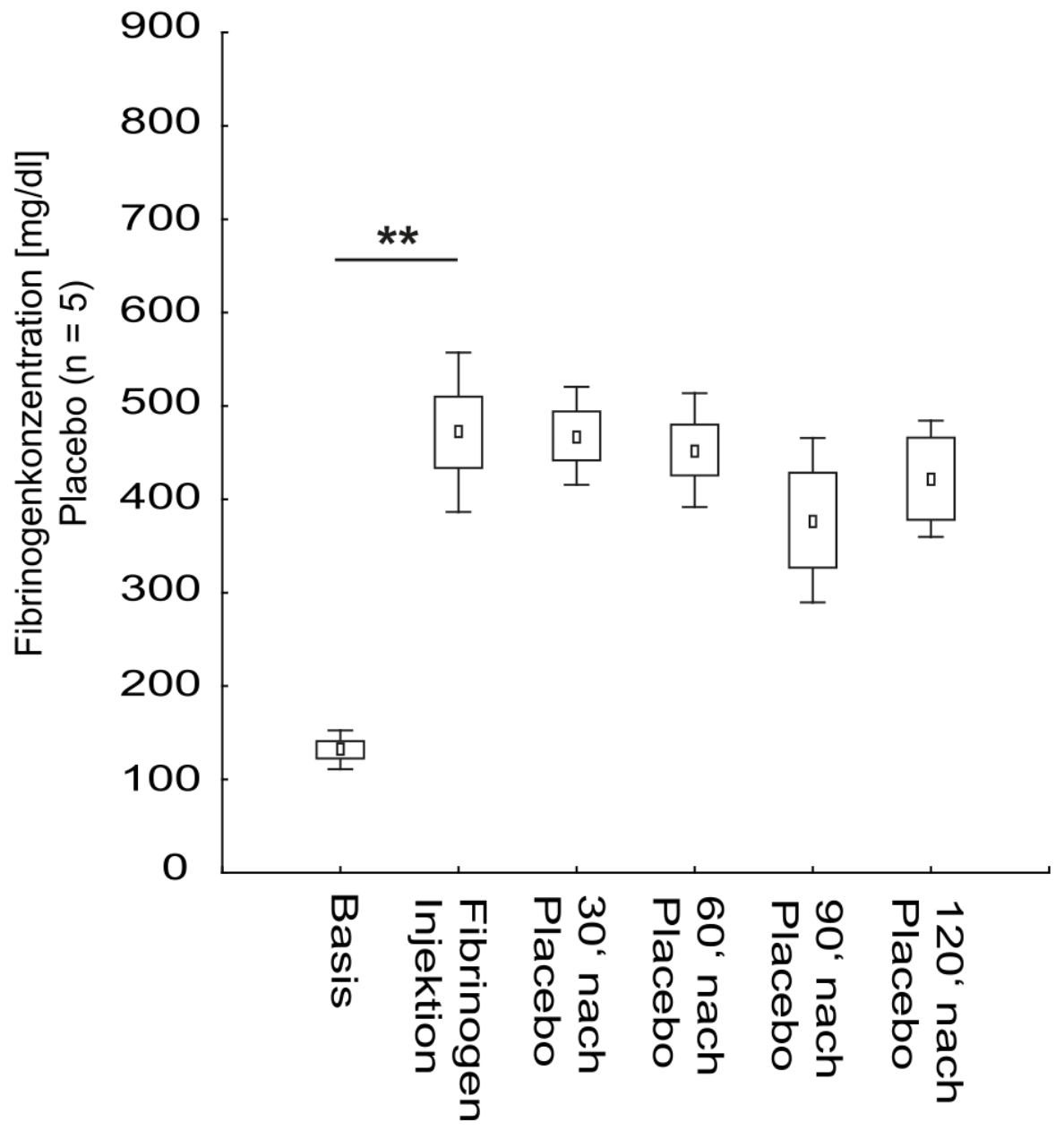

Abbildung 12: Plasmafibrinogenkonzentration in $\mathrm{mg} / \mathrm{dl}$ im Blut der Placebo-Gruppe zu den sechs Messzeitpunkten.

Das Serumfibrinogen zeigte sich nach Fibrinogen-Injektion signifikant erhöht. ** P-Wert $<0,01$

\subsubsection{Plasmafibrinogenkonzentration der Methylprednisolon-Gruppe im} Versuchsverlauf

Zeitgleich mit den Basisparametern wurde eine PFK von im Mittel 122,2 mg/dl (R = $107-147 ; \pm 15$ ) bestimmt. Unmittelbar nach der Fibrinogengabe stieg die Konzentration signifikant um 342,4 \% auf einen Wert von im Mittel 540,6 mg/dl an (R $=486-599 ; \pm 53 ; p<0,01)$. Auch 30 Minuten nach Therapiebeginn blieben die Fibrinogenwerte nahezu unverändert hoch bei durchschnittlich $498 \mathrm{mg} / \mathrm{dl}(\mathrm{R}=420$ - 549; $\pm 50,7)$. Bis zur Beendigung des Versuches veränderten sich die Laborparameter nicht mehr signifikant. 120 Minuten nach Therapie mit Methylprednisolon wurden die letzten Werte bei 477,6 mg/dl gemessen. $(R=362-669 ; \pm 120,4)$. 
Die PFK stieg nach Fibrinogeninfusion zur Hörsturzinduktion signifikant an und verblieb innerhalb der untersuchten 150 Minuten auf einem ähnlich hohen Niveau.

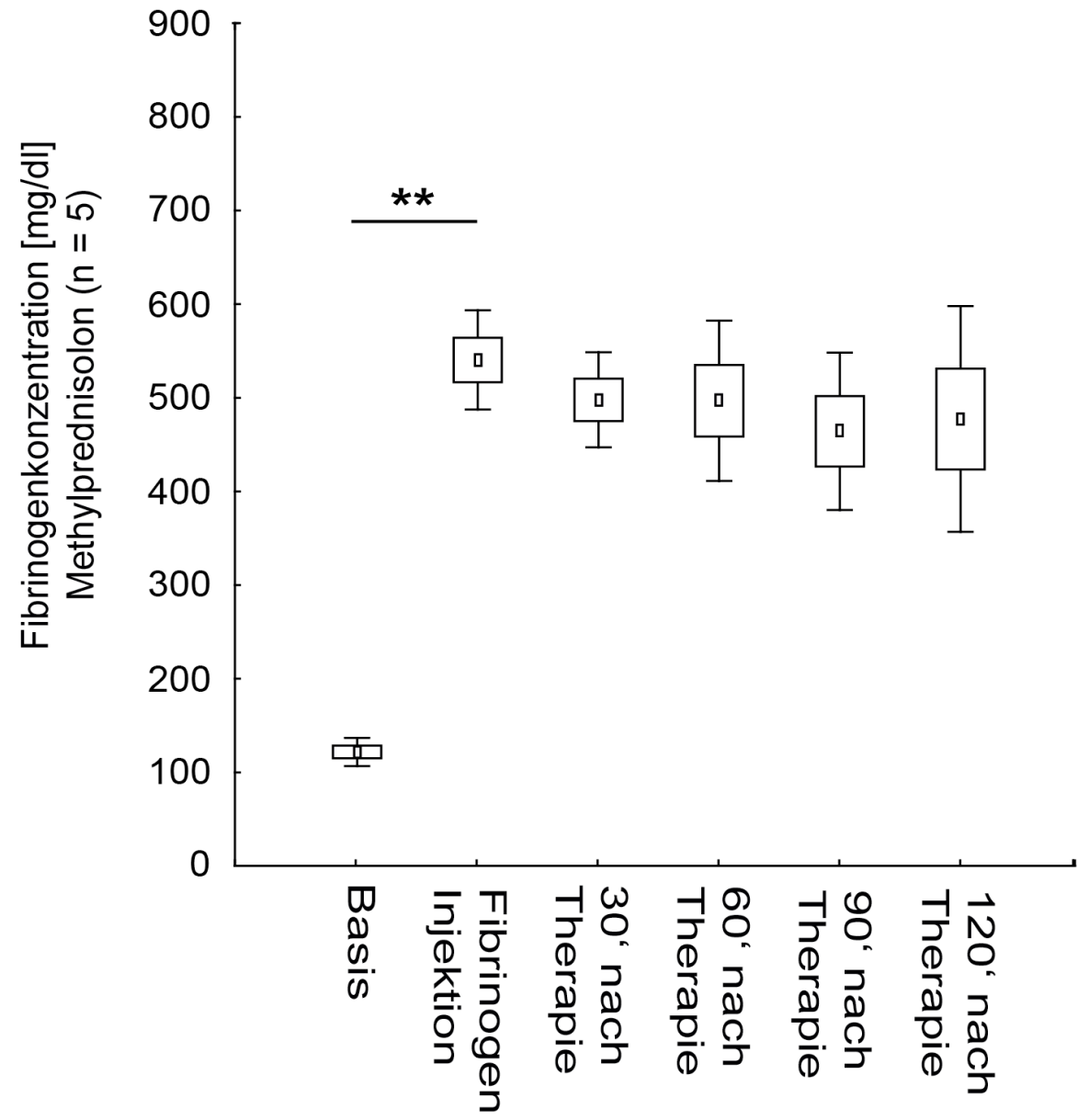

Abbildung 13: Plasmafibrinogenkonzentration in mg/dl im Blut der Methylprednisolon-Gruppe zu den sechs Messzeitpunkten.

Das Serumfibrinogen zeigte sich nach Fibrinogen-Injektion signifikant erhöht. ** P-Wert < 0,01

\subsubsection{Die Plasmafibrinogenkonzentration im Gruppenvergleich}

Zum Zeitpunkt der Basisparameterbestimmung lagen die Plasmafibrinogenwerte in beiden Versuchsgruppen auf einem ähnlichen Niveau. Im Mittel lagen die Werte der Plasmafibrinogenkonzentration (PFK) in der Placebo-Gruppe bei 131,4 mg/dl $(\mathrm{R}=110-166 ; \pm 21)$, in der Methylprednisolon-Gruppe bei 122,2 mg/dl $(\mathrm{R}=107$ - 147; \pm 15 ). In beiden Versuchsgruppen stieg die PFK nach Fibrinogengabe signi- 
fikant an. In der Placebo-Gruppe um 260,4 \% auf einen Wert von im Mittel 473,6 $\mathrm{mg} / \mathrm{dl}(\mathrm{R}=345-567 ; \pm 85,3 ; \mathrm{p}<0,01)$, in der Methylprednisolon-Gruppe um 342,4 $\%$ auf einen Wert von im Mittel 540,6 mg/dl $(\mathrm{R}=486-599 ; \pm 53 ; \mathrm{p}<0,01)$. Im Versuchsverlauf blieben die Werte auf einem vergleichbar hohen Niveau und es kam in keiner der beiden Gruppen zu einer signifikanten Änderung.

\subsection{Hörschwelle}

\subsubsection{Die Hörschwelle der Placebo-Gruppe im Versuchsverlauf}

Bei initialer Bestimmung ergab sich eine Hörschwelle (HS) von im Mittel $16 \mathrm{~dB}$ (R $=10-20$; Standardabweichung \pm 5,5). Nach Fibrinogengabe (330 mg Fibrinogen/kg KG), stieg die HS auf durchschnittlich $30 \mathrm{~dB}$ um 87,5 \% an (R=10-50; \pm 15,8). Dieser Anstieg war statistisch signifikant $(p<0,012)$. Im Verlauf, auch nach Applikation von Kochsalzlösung als Placebo, ergab sich keine weitere signifikante Änderung der Hörschwelle. Jedoch ließ sich eine geringe Steigerung der HS mit fortlaufender Dauer des Versuches erkennen. Es ergaben sich durchschnittliche Werte von $36 \mathrm{~dB}$ bei $90 \mathrm{~min}$. $(\mathrm{R}=30-40 ; \pm 5,5)$ sowie $35 \mathrm{~dB}$ bei $120 \mathrm{~min}$. $(R=30$ - 40; S: 7,1) nach Placebogabe. 


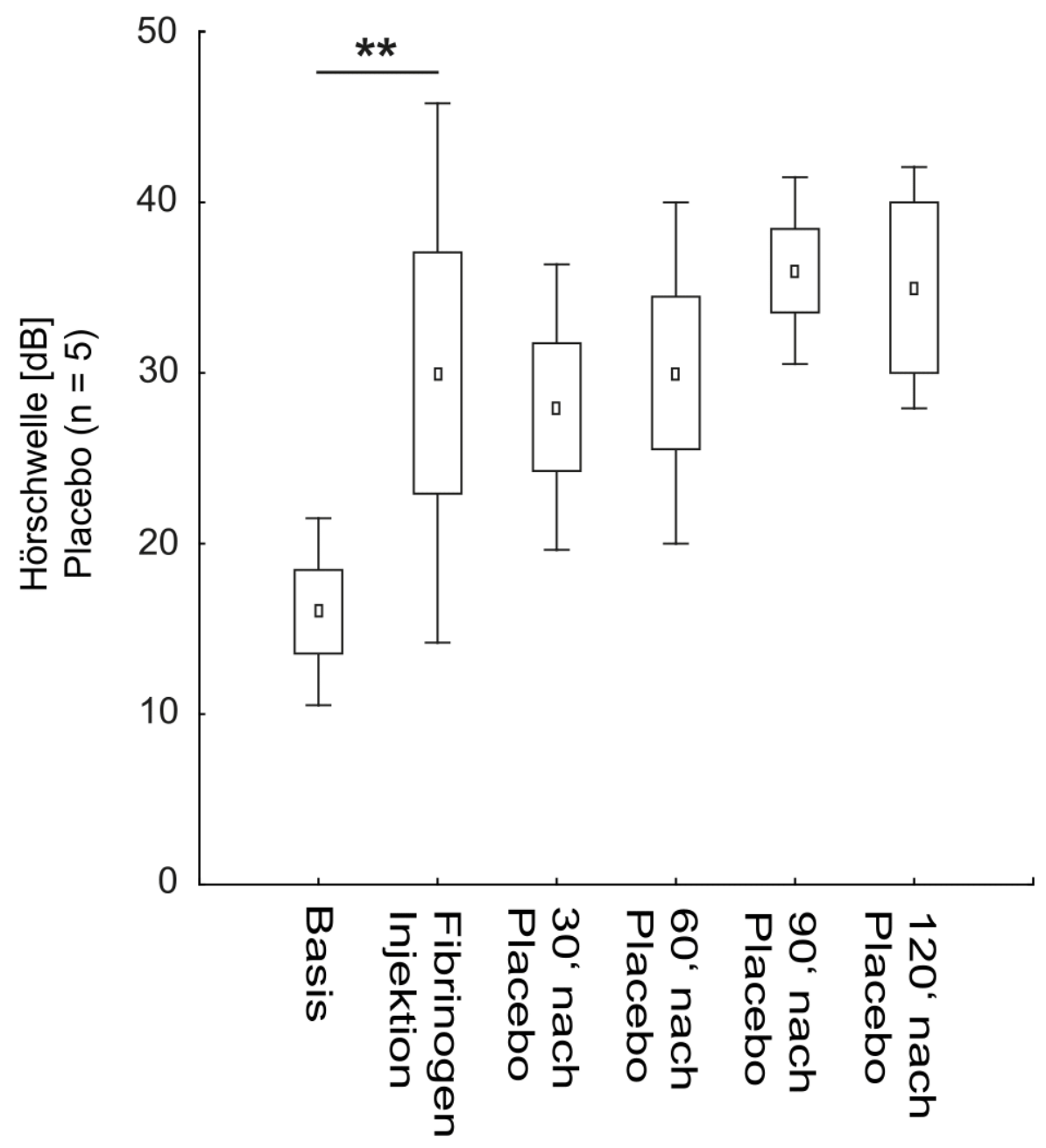

Abbildung 14: Hörschwellenbestimmung der Placebo-Gruppe in dB zu den sechs Messzeitpunkten. Die Hörschwelle stieg nach Fibrinogen-Injektion signifikant von $16 \mathrm{~dB}$ auf $30 \mathrm{~dB}$ an. ${ }^{* *} \mathrm{P}-$ Wert $<0,01$

\subsubsection{Die Hörschwelle der Methylprednisolon-Gruppe im Versuchsverlauf}

In der Versuchsgruppe der mit Methylprednisolon behandelten Tiere kam es nach Fibrinogengabe zu einem Anstieg der HS von einem Ausgangswert der im Durchschnitt bei $10 \mathrm{~dB}(\mathrm{R}=0$; Standardabweichung \pm 0) lag um $120 \%$ auf durchschnittlich $22 \mathrm{~dB}(\mathrm{R}=20-30 ; \pm 4,5)$. Dieser Anstieg war statistisch signifikant $(\mathrm{p}<0,043)$. Im weiteren Verlauf ergab sich keine weitere signifikante Veränderung der Hörschwelle. Jedoch ließ sich auch in der Gruppe der mit Methylprednisolon behandelten Tiere eine geringe Steigerung der HS mit fortlaufender Dauer des Versuches erkennen. Nachdem die Werte 30 Minuten nach Therapiebeginn nahezu unverändert geblieben waren, zeigte sich ein leichter Anstieg auf im Mittel 24 dB nach 60 
min. $(R=20-30 ; \pm 5,5)$. Daraufhin veränderte sich die HS im Mittel bei der Messung nach 90 min. nicht, stieg dann zum Ende des Versuches jedoch noch einmal auf 32 $\mathrm{dB}(\mathrm{R}=10-50 ; \pm 17,9)$.

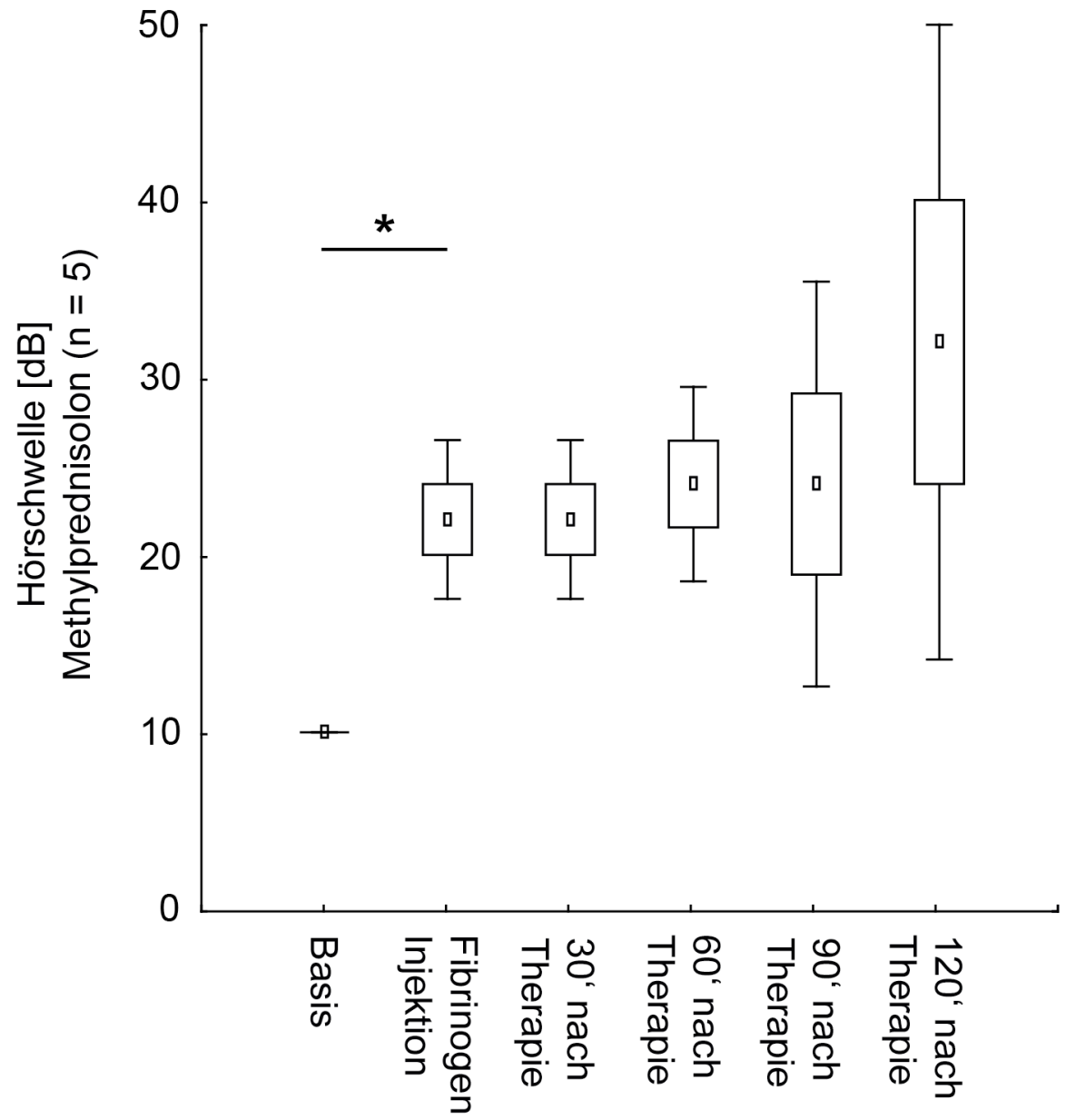

Abbildung 15: Hörschwellenbestimmung der Methylprednisolon-Gruppe in dB zu den sechs Messzeitpunkten.

Die Hörschwelle stieg nach Fibrinogen-Injektion signifikant von $10 \mathrm{~dB}$ auf $22 \mathrm{~dB}$ an. * P-Wert $<0,05$

\subsubsection{Die Hörschwelle im Gruppenvergleich}

Zum Zeitpunkt der Basisparameterbestimmung lagen die Werte der Hörschwelle (HS) in beiden Versuchsgruppen auf einem ähnlichen Niveau. Im Mittel lagen die Werte der HS in der Placebo-Gruppe bei 16 dB (R = 10 - 20; Standardabweichung $\pm 5,5)$, in der Methylprednisolon-Gruppe bei $10 \mathrm{~dB}(\mathrm{R}=0$; Standardabweichung \pm 
0). In beiden Versuchsgruppen stieg die HS nach Fibrinogengabe signifikant an. In der im Folgenden mit Placebo behandelten Gruppe um 87,5 \% auf durchschnittlich $30 \mathrm{~dB}(\mathrm{R}=10-50 ; \pm 15,8)$, in der im Folgenden mit Methylprednisolon behandelten Gruppe um $120 \%$ auf durchschnittlich 22 dB (R = 20-30; $\pm 4,5)$. Im Verlauf nach Therapie mit entweder Methylprednisolon oder Placebo ergab sich im Vergleich der beiden Versuchsgruppen zueinander kein signifikanter Unterschied in der Hörschwelle. Jedoch ließ sich in beiden Versuchsgruppen eine geringe Zunahme der HS mit fortlaufender Dauer des Versuches erkennen.

\subsection{Cochleärer Blutfluss}

\subsubsection{Die relative Änderung des cochleären Blutflusses der Placebo-Gruppe im Versuchsverlauf}

Der cochleäre Blutfluss zu Beginn des Versuches wurde als Basiswert mit der Größe 1 festgelegt. Bei der Messung zeigte sich unmittelbar nach Fibrinogengabe ein nahezu unveränderter Blutfluss. Im Versuchsverlauf sank der cochleäre Blutfluss unter den relativen Wert von 1 des Ausgangswertes des Blutvolumenstroms (Q). Zum Zeitpunkt der Messung 30 Minuten nach Therapiebeginn waren Werte von durchschnittlich 0,88 relativ zum Basalwert zu bestimmen $(R=0,7-1,1 ; \pm 0,18)$. 60 Minuten nach Therapiebeginn sank der Blutfluss noch weiter auf einen Wert von $0,68(R=0,4-0,9 ; \pm 0,28)$ und erreichte damit den tiefsten Messwert des Versuches. Zum Zeitpunkt der letzten Messung ergab sich ein Durchschnittswert von $0,7(\mathrm{R}=0 ; \pm 0,02)$.

Der cochleäre Blutfluss ist nach Fibrinogengabe im Verlauf vom Ausgangswert 1 um etwa 30 \% gesunken. Dieser deutliche Trend zu einer reduzierten cochleären Mikrozirkulation war statistisch nicht signifikant $(\mathrm{p}=0,52)$. 


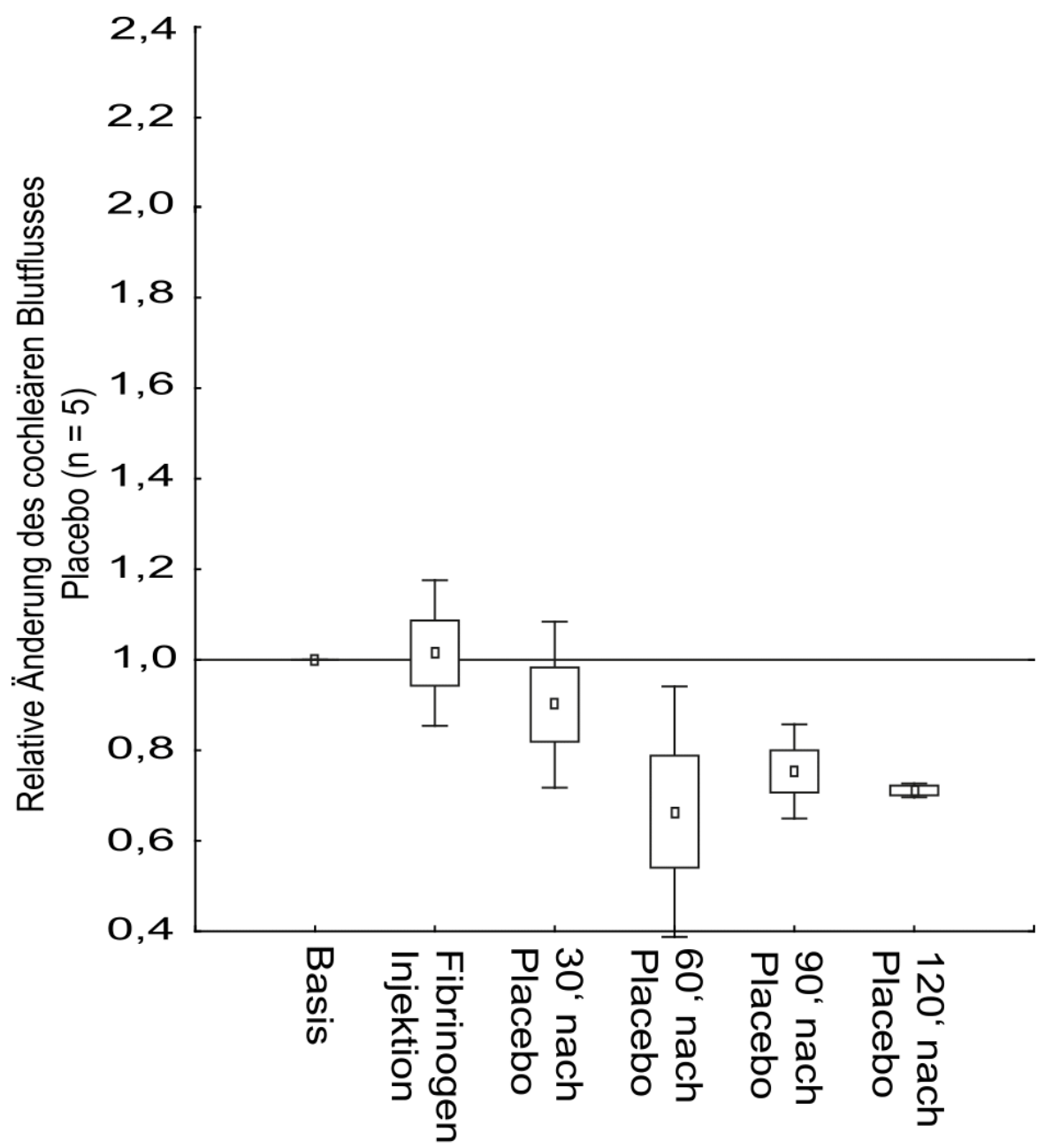

Abbildung 16: Relative Änderung des cochleären Blutflusses der Placebo-Gruppe zu den sechs Messzeitpunkten.

Der cochleäre Blutfluss steigt nach Fibrinogen-Injektion leicht. Im Verlauf des Experimentes wird ein nicht signifikantes Absinken beobachtet.

\subsubsection{Die relative Änderung des cochleären Blutflusses der Methylpredniso-}

\section{lon-Gruppe im Versuchsverlauf}

In der Gruppe der mit Methylprednisolon behandelten Tiere zeichnete sich bei der Messung unmittelbar nach Fibrinogengabe eine statistisch nicht signifikante Erhöhung des cochleären Blutflusses ab. Die Fließgeschwindigkeit lag im Mittel bei 1,22 $(R=0,9-1,6$; Standardabweichung $\pm 0,26)$. Bei den weiteren Messzeitpunkten nach Medikamentengabe sank der cochleäre Blutfluss unter den relativen Wert 1 der Anfangsgeschwindigkeit. Eine erste signifikante Änderung zeigte sich zwischen der Messung nach Fibrinogengabe und der Messung 90 Minuten nach Therapiebe- 
ginn. Der Blutvolumenstrom lag bei $0,7(R=0,5-1 ; \pm 0,28 ; p<0,007)$. Dies entspricht einer prozentualen Verlangsamung von 42,62 \%. Zum Zeitpunkt der letzten Messung wurden Durchschnittswerte gemessen, die denen der vorangegangenen Testung entsprachen. Damit war also auch zu diesem Zeitpunkt eine signifikante Verlangsamung des Blutvolumenstroms zwischen der Messung zum Zeitpunkt der Fibrinogengabe erkennbar. Der relative Wert lag zu diesem Zeitpunkt ebenfalls im Mittel bei $0,7(R=0,5-0,9 ; \pm 0,14 ; p<0,005)$.

Eine Verlangsamung des Blutflusses der cochleären Gefäße konnte im Gesamtverlauf des Versuches verzeichnet werden.

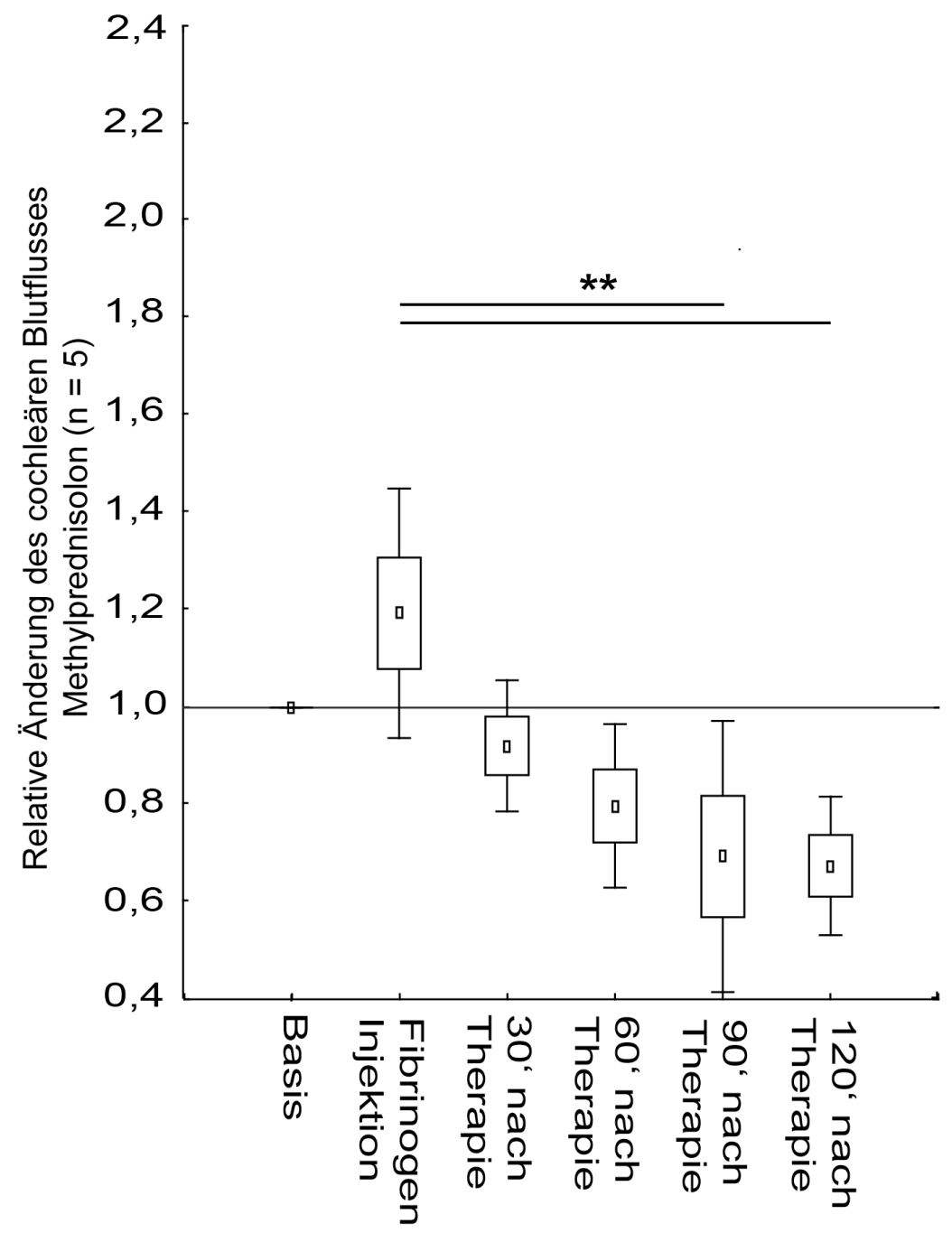

Abbildung 17: Relative Änderung des cochleären Blutflusses der Methylprednisolon-Gruppe zu den sechs Messzeitpunkten.

Der cochleäre Blutfluss sinkt zwischen der Messung nach Fibrinogen-Injektion und den Messzeitpunkten 90 und 120 Minuten nach Therapiebeginn signifikant von 1,22 auf 0,7 und 0,68. ${ }^{* *}$ p-Wert $<0,01$ 


\subsubsection{Die relative Änderung des cochleären Blutflusses im Gruppenvergleich}

Der cochleäre Blutfluss wurde für beide untersuchten Gruppen zu Beginn des Versuches als Basiswert mit der Größe 1 festgelegt. In keiner der beiden Versuchsgruppen ergab sich eine signifikante Änderung nach Fibrinogengabe. In der Placebo-Gruppe ist der cochleäre Blutfluss nach Fibrinogengabe im Verlauf um etwa 30 \% gefallen und betrug zum Zeitpunkt der letzten Messung im Durchschnitt 0,7 (R = $0 ; \pm 0,02)$. In der Methylprednisolon-Gruppe stiegen die Werte, anders als die Werte der Vergleichsgruppe, nach Fibrinogengabe zunächst an auf im Mittel 1,22 (R = $0,9-1,6 ; \pm 0,26)$. Im weiteren Versuchsverlauf zeigte sich jedoch auch in dieser Gruppe ebenfalls ein Absinken des cochleären Blutflusses. Die Werte sanken bis zur finalen Messung ebenfalls auf im Mittel 0,7 ( $R=0,5-0,9 ; \pm 0,14 ; p<0,005)$. Zu diesem Zeitpunkt zeigt sich auch im Vergleich der beiden Versuchsgruppen zueinander kein signifikanter Unterschied in der cochleären Mikrozirkulation.

\subsection{Arterieller Mitteldruck}

\subsubsection{Der arterielle Mitteldruck der Placebo-Gruppe im Versuchsverlauf}

Die Kontrolle des arteriellen Mitteldruckes (MAP) erfolgte zur Beurteilung des Allgemeinzustandes der Versuchstiere im Rahmen der Narkose. Signifikante Änderungen konnten während der Parameterbestimmung nicht gemessen werden. Zum Zeitpunkt der ersten Parameterbestimmung lag der MAP durchschnittlich bei 43,6 mmHg $(\mathrm{R}=32,1-53,9 ; \pm 8,1)$. Während des Versuches ließen sich geringe Schwankungen um den initial verzeichneten Ausgangswert messen. Mit Fortlauf des Experimentes sank der MAP auf einen Mittelwert von 26,7 $\mathrm{mmHg}$ ( $\mathrm{R}=$ 20,5 30,$9 ; \pm 6,7$ ) zum Zeitpunkt 90 min nach Medikamentengabe. Insgesamt also fiel der MAP um 38,8 \%.

Zum Zeitpunkt 120 min stehen keine aussagekräftigen Durchschnittswerte zur Verfügung, da nicht bei allen Tieren bis zum Schluss des Experimentes Werte durch die Blutdruckmesssonde generiert werden konnten. Grund war ein wiederholt auftretender Verschluss der Messarterie um den Sondenkopf. 


\subsubsection{Der arterielle Mitteldruck der Methylprednisolon-Gruppe im Ver- suchsverlauf}

In der Kohorte der Tiere, die mit Methylprednisolon therapiert wurden, lag der arterielle Mitteldruck (MAP) vor Fibrinogen-Injektion bei 43,6 mmHg ( $\mathrm{R}=34,3-$ $57,3, \pm 8,4)$. Auch in dieser Versuchsgruppe ließ sich kein signifikanter Anstieg oder Abfall im Versuchsverlauf ausmachen. Zu erkennen war auch hier ein Trend zu einem stetigen leichten Abfall des MAP über das gesamte Intervall der Parameterbestimmung. 120 min nach Medikamentengabe lag der MAP bei durchschnittlich 37,3 mmHg (R = 22,5 - 48,8; $\pm 13,5)$. Damit war ein Abfall des MAP von 14,4 \% zu verzeichnen. 


\section{Diskussion}

Bis heute ist für das Krankheitsbild des akuten idiopathischen sensorineuralen Hörverlusts kein allgemeingültiger der Erkrankung zugrundeliegender Pathomechanismus bekannt. Es werden verschiedene Theorien diskutiert, konnten bisher jedoch nicht hinreichend belegt werden. In diesem Kontext ist unter anderem die Virusgenese zu nennen, die seit Beginn der Hörsturzforschung in den 50er Jahren als eine mögliche Ursache für das Auftreten des Krankheitsbildes vermutet wird (Van Dishoeck und Bierman 1957; O'neill 1960). Allerdings konnte auch der Beweis einer Virusätiologie bisher nicht erbracht werden. Diskutiert wird zudem, dass es sich bei den wenigen Fallbeschreibungen eher um ein zufälliges Zusammentreffen von Infektion und plötzlicher Hörminderung handelt (Pitkäranta und Julkunen 1998b; Sheu et al. 2012).

Zum anderen ist die Theorie der vaskulären Genese zu nennen. Ein Zusammenhang zwischen Mikroembolien im Gefäßgebiet der A. labyrinthi und der Stria vascularis, verursacht durch eine vorausgegangene Änderung der Blut- und Plasmaviskosität, sollen demnach für das Auftreten eines Hörsturzes ursächlich sein (Kimura 1986). In diesem Sinne wurde ein vaskulärer Ursprung entweder als primäre Ursache oder als Teil einer multifaktoriellen Genese postuliert. Darüber hinaus könnte eine beeinträchtigte cochleäre Mikrozirkulation auch die gemeinsame Endstrecke anderer ätiologischer Faktoren sein.

Daher sollte in der vorliegenden Arbeit die Wirksamkeit des aktuellen therapeutischen Standards, der Therapie mit Glukokortikoiden, an einem Tiermodell für einen vaskulär bedingten Hörverlust untersucht werden. Hierbei wurde mittels Herbeiführen einer akuten Hyperfibrinogenämie ein akuter Hörverlust induziert. Das Tiermodell erlaubte unter dem Einfluss verschiedener therapeutischer Strategien die simultane Messung der Hörschwelle sowie der cochleären Mikrozirkulation (Canis et al. 2012; Ihler et al. 2012).

\subsection{Das Hörvermögen in Abhängigkeit vom cochleären Blutfluss}

In der vorliegenden Arbeit wird die Minderversorgung des Corti-Organs als der zu Grunde liegende Auslöser für den akuten idiopathischen sensorineuralen Hörverlust angenommen. Diese Theorie wird in der Wissenschaft diskutiert und wurde in 
einer Vielzahl an Studien untersucht (Hesch 1982; Maass 1982; Kimura 1986). Sie gilt heute als einer der wahrscheinlichsten dem Hörsturz zu Grunde liegende Pathomechanismen (Boenninghaus und Lenarz 2004).

Aus der A. inferior anterior cerebrelli oder in selteneren Fällen aus der A. basilaris entspringend, versorgt die A. labyrinthi das Innenohr. Sie zieht in den Meatus acusticus internus, indem sie sich in die A. vestibularis und die A. cochlearis communis aufteilt. Aus dieser A. cochlearis communis wiederum stammen die A. vestibulocochlearis und die A. cochlearis propia. Letztgenannte bildet in der Scala vestibuli Spiralgefäße aus, die über ein Kapillarnetz als funktionelle Endarterien die Stria vascularis versorgen (Graumann und Sasse 2005).

Das Kapillarnetz der Stria vaskularis ist mitverantwortlich für die Bildung der Endolymphe. Ein ausreichend hoher Blutfluss in den Präkapillaren und Kapillaren sichert dabei die Kaliumversorgung der Endolymphe im Ductus cochlearis. Die ausreichende Blutversorgung ist folglich obligat, um das endolymphatische Potential von $+80 \mathrm{mV}$ bilden zu können (Nin et al. 2008). Erst durch Erreichen dieses Potentials können die inneren Haarzellen des Corti-Organs, nach Auslenkung der äußeren Haarzellen durch die Tektorialmembran, depolarisiert werden. Als Folge wird die schallübertragene Auslenkung in einen elektronischen Impuls umgewandelt, der dann an das sich anschließende afferente Neuron weitergegeben wird. Bei rheologischen Störungen mit Minderdurchblutung der Kapillaren der Stria vascularis kann die Potentialdifferenz zwischen Endolymphe und dem Inneren der Haarzellen nicht aufrechterhalten werden. Auch eine Sauerstoffunterversorgung des Corti-Organs kann durch thrombotische Geschehen oder rheologische Störungen bedingt sein und die Funktion empfindlich stören. Die Aufrechterhaltung des endolymphatischen Potentials steht in unmittelbarer Abhängigkeit vom Sauerstoffpartialdruck (Nuttall und Lawrence 1980). Ein ausreichender cochleärer Blutfluss und insbesondere eine ausreichende Durchblutung der Stria vascularis ist maßgebend für ein intaktes Hörvermögen, da eine ausreichende Sauerstoffversorgung der Endolymphe unabdingbar für das Aufrechterhalten der ATPKonzentration ist. Eine anhaltende Ischämie hingegen führt zum Absinken der ATP-Konzentration im Corti-Organ, und die endocochleären Prozesse kommen zum Erliegen womit die Transduktion der Schallwellen und die Ausbildung von elektrischen Signalen durch die Haarzellen nicht mehr möglich ist (Thalmann et al. 
1972; Konishi 1979). Auch die An- und Abwesenheit von Zytokinen wie beispielsweise dem Tumornekrosefaktor- $\alpha$ nimmt über Vermittlung von weiteren Signalkaskaden Einfluss auf den cochleären Blutfluss (Scherer et al. 2010; Bertlich et al. 2017).

Aus diesem Grund stand der Parameter des cochleären Blutflusses in der vorliegenden Arbeit immer in engem Bezug zur untersuchten Hörschwelle. Die Ergebnisse lassen dabei einen engen Zusammenhang zwischen induzierter Hörminderung und verringertem cochleärem Blutfluss vermuten, da beide Parameter eine deutliche Veränderung nach Fibrinogeninjektion beschreiben. Es kommt zu einem signifikanten Anstieg der Hörschwelle, wohingegen sich der cochleäre Blutfluss um etwa $30 \%$ reduziert. Der enge Zusammenhang einer Mikrozirkulationsstörung durch akute Hyperfibrinogenämie und damit einhergehenden Schallempfindungsschwerhörigkeiten wurde in Vorarbeiten mit Hilfe des der Arbeit zugrundeliegenden Tiermodells bereits dargestellt (Ihler et al. 2012).

\subsection{Fibrinogen als Einflussfaktor bei der Entstehung eines akuten Hörver- lusts}

Dem 340 kDa großem Plasmaglykoprotein Fibrinogen wird eine entscheidende Rolle in der Entstehung von kardiovaskulären und zerebrovaskulären Erkrankungen beigemessen. Lominadze et al. beschrieben den Einfluss des Moleküls auf die Mikrozirkulation des Körpers. Steigende Fibrinogenkonzentrationen verursachen Veränderungen der rheologischen Eigenschaften des Blutes wie beispielsweise eine erhöhte Plasmaviskosität, eine erhöhte Erythrozyten- und Thrombozytenaggregation und eine mögliche Schädigung der Endothelschichten. Es wird ein Zusammenhang zwischen erhöhten Plasmafibrinogenkonzentrationen und schweren Allgemeinerkrankungen wie beispielsweise arterielle Hypertonie, Diabetes mellitus und dem Apoplex hergestellt (Lominadze et al. 2010).

In diesem Kontext wird auch der Zusammenhang zwischen pathologisch erhöhten Fibrinogenkonzentrationen im Blut und dem Auftreten eines Hörsturzes diskutiert (Suckfüll und Hearing Loss Study Group 2002; Ihler et al. 2012). In einer Kasuistik wird zudem von einer Patientin berichtet, die neben einer plötzlichen Hörminderung innerhalb von nur wenigen Wochen zusätzlich an einem akuten Verschluss 
der Zentralvene der Retina erkrankte. Bei ihr wurde eine erhöhte Plasmafibrinogenkonzentration gemessen. Diskutiert wurde die akute Störung des mikrovaskulären Blutflusses als ein für beide Erkrankungen zugrundeliegender möglicher gemeinsamer Pathomechanismus mit dem Vorliegen einer Hyperfibrinogenämie als Risikofaktor (Glacet-Bernard et al. 2008).

Aufgrund dieser möglichen Zusammenhänge von Hyperfibrinogenämie und der Entstehung eines Hörsturzes lag der vorliegenden Arbeit ein Tiermodell für einen durch Hyperfibrinogenämie bedingten akuten Hörverlust zugrunde.

\subsection{Glukokortikoide zur Behandlung des Hörsturzes}

Die Glukokortikoidtherapie gilt in Deutschland als der aktuelle therapeutische Standard, wenngleich der tatsächliche Nutzen bei unzureichender Studienlage noch nicht abschließend belegt wurde (Conlin und Parnes 2007; Wei et al. 2013).

Die Therapie mit Kortikosteroiden basiert auf der Annahme inflammatorischer oder Immunsystem-modulierender Prozesse als pathogenetische Ursache des Hörsturzes. Ein therapeutischer Effekt könnte auf der antiinflammatorischen und antiödematösen Wirkung wie auch auf einer erhöhten Katecholamin-Empfindlichkeit mit konsekutiver cochleärer Blutflusssteigerung beruhen. Auf diese Weise werden beispielsweise proinflammatorische Mediatoren wie die Eikosanoide (Prostaglandin, Prostazyklin, Thromboxan, Leukotrien, platelet activating factor) und Zytokine (Interleukin 1 - 12, Interferon $\alpha$ und $\gamma$, Tumornekrosefaktor- $\alpha$ ) gehemmt. Des Weiteren wird die Adhäsion und transendotheliale Migration von freien proinflammatorischen Zellen zu den Entzündungsherden unterbunden (Lamm et al. 1999).

In vorausgegangenen Untersuchungen wurde gezeigt, dass Fibrinogen die Synthese von proinflammatorischen Zytokinen wie z. B. Tumornekrosefaktor- $\alpha$ induziert (Jensen et al. 2007). Durch die Aktivierung der vaskulären Sphingosin-1-Phosphat Kaskade reduziert Tumornekrosefaktor- $\alpha$ den cochleären Blutfluss (Scherer et al. 2010; Ihler et al. 2013). Aus diesem Grund sollten inflammatorische und mikrozirkulationsbeeinflussende Faktoren nicht länger getrennt voneinander betrachtet werden, sondern vielmehr in einem Zusammenhang. Da verschiedene Krankheiten und Mechanismen, wie beispielsweise Infektionen, systemische Entzündungsreaktionen oder auch Autoimmunerkrankungen zu einer Ausschüttung von Tumorne- 
krosefaktor- $\alpha$ führen könnte dies auch in Zusammenhang mit der Genese eines akuten Hörverlust stehen.

Die Anwesenheit von Glukokortikoidrezeptoren im vestibulocochlearen System des Menschen wurde erstmals durch Rarey und Curtis beschrieben (Rarey und Curtis 1996). Dabei wurde die höchste Konzentration von Rezeptoren im Ligamentum spirale gesehen. Hierin kann der Ansatz, akute idiopathische Innenohrerkrankungen durch Glukokortikoidgabe zu behandeln, bekräftigt werden.

Ziel dieser Arbeit war es folglich, die Wirksamkeit des aktuell zur Behandlung des Hörsturzes empfohlenen therapeutischen Standards Prednisolon in einem Tiermodell für einen durch akute Hyperfibrinogenämie bedingten vaskulären Hörverlust zu prüfen. Bei beiden Versuchsgruppen war nach Fibrinogengabe ein signifikanter Anstieg der Hörschwelle zu verzeichnen. Nach Applikation der Prüfsubstanzen Prednisolon und Placebo konnte im weiteren Versuchsverlauf diese Schwelle nicht wieder gesenkt werden. Die Ergebnisse bestätigen den aus Voruntersuchungen bekannten Zusammenhang zwischen einer pathologisch erhöhten Plasmafibrinogenkonzentration und einer daraus resultierenden Hörminderung (Ihler et al. 2012). Eine Wirksamkeit der Glukokortikoidtherapie war in diesem Tiermodell für einen vaskulär bedingten Hörverlust nicht gegeben.

Auch in der Literatur ist die Wirksamkeit von Kortikosteroiden zur Behandlung des Hörsturzes kontrovers diskutiert. Nicht selten erhalten Patienten im Falle eines plötzlich auftretenden Hörverlusts zudem eine Vielzahl von Behandlungen, sodass mögliche therapeutische Effekte nicht immer einer bestimmten Therapie zuzuordnen sind. Erschwerend kommt auch eine nicht unerhebliche Spontanheilungsrate hinzu. Oft lässt sich somit auch in klinischen Studien nicht abschließend beantworten, ob die beobachtete Remission der Hörstörung auf eine Glukokortikoidtherapie zurückzuführen ist. Der Anteil an Spontanheilungen wurde in der Literatur äußerst variabel beschrieben. Mattox und Simmons sahen in einer prospektiven Studie, dass 65 \% der untersuchten Patienten das vollständige Hörvermögen auch ohne Medikamentengabe spontan wiedererlangten. Weitere $8 \%$ wiesen eine Verbesserung des Hörvermögens um mindestens $30 \mathrm{~dB}$ auf (Mattox und Simmons 1977). Eine weitere Untersuchung fasst zusammen, dass etwa $25 \%$ der untersuchten Patienten ihr Hörvermögen voll und weitere 50 \% einen Teil ih- 
res Hörvermögens spontan wieder erlangten (Vasama und Linthicum 2000). Guyot und Thielen beschreiben zudem, dass etwa $40 \%$ der nicht behandelten Patienten mit einer akut auftretenden Schallempfindungsstörung eine spontane Erholung des Hörvermögens von durchschnittlich 20 dB erfuhren (Guyot und Thielen 2000).

Bisherige klinische Studien zeigten teils widersprüchliche Ergebnisse zur Wirksamkeit von Glukokortikoiden in der Behandlung des Hörsturzes. Wilson et al beschreiben nach Glukokortikoidtherapie eine Hörverbesserung in 61 \% der Fälle wohingegen es nach Placebobehandlung in nur 32 \% der Fälle zu einer Hörverbesserung kam (Wilson et al. 1980). Auch Moskowitz et al. beschreiben eine signifikante Hörverbesserung um mindestens 50 \% bei $89 \%$ der mit Kortikosteroiden behandelten Patienten, wohingegen lediglich $44 \%$ der unbehandelten Patienten eine um 50 \% verbesserte Hörleistung zeigten. Anders als Wilson et al. sahen sie keinen Zusammenhang zwischen dem Alter der Patienten und der Rate der Hörverbesserung (Moskowitz et al. 1984). Auch die Arbeitsgruppe um Alexiou et al. beschrieb einen Behandlungsvorteil bei Gabe von Kortikosteroiden. In die retrospektive Untersuchung wurden 603 Hörsturzpatienten eingeschlossen. Die eine Gruppe erhielt lediglich die rheologisch wirksamen Medikamente Pentoxifyllin oder HAES 6 \%, wohingegen die andere Gruppe zusätzlich mit 500 - 1000 mg Prednisolon behandelt wurde. Es zeigte sich eine signifikante Besserung des Hörvermögens bei jenen, die zusätzlich Kortikosteroide erhielten (Alexiou et al. 2001). Dem gegenüber stehen zwei weitere Studien. Nosrati-Zarenoe et al. konnten keinen signifikanten Unterschied in der Hörverbesserung zwischen der Glukokorikoidgruppe und der Placebo-Gruppe darstellen. Die durchschnittliche Hörverbesserung nach Gabe von initial $60 \mathrm{mg}$ Prednisolon für 3 Tage lag bei 25,5 dB und nach drei Monaten bei 39 dB. Nach Placebogabe betrug die Verbesserung des Hörvermögens 26,4 dB nach acht Tagen und 35,1 dB nach drei Monaten (NosratiZarenoe und Hultcrantz 2012). Eine weitere randomisierte Studie, verglich die systemische Gabe von Glukokortikoiden (Prednison per os $1 \mathrm{mg} / \mathrm{kg} \mathrm{KG}$ ) mit einer Sauerstoff- und Kohlensäure-Inhalationstherapie (Karbogen 5 \% CO2 + 95 \% Sauerstoff) sowie einer Placebobehandlung und konnte ebenfalls keine Überlegenheit einer Therapieform gegenüber der anderen darstellen. Die Gruppe der mit Prednisolon behandelten Patienten zeigte eine Verbesserung des Hörvermögens von im 
Durchschnitt $60 \%$ nach sechstägiger Behandlung und von $80 \%$ im späteren Verlauf. Die Placebo-Gruppe zeigte zu entsprechenden Zeitpunkten eine Hörverbesserung um durchschnittlich $63 \%$ und $81 \%$. Ein signifikanter Unterschied blieb demnach aus (Cinamon et al. 2001).

Um entsprechend hohe Glukokortikoidkonzentrationen in der Perilymphe des Innenohres des Menschen nachweisen zu können, sind hohe systemisch applizierte Medikamentendosen erforderlich. Niedermeyer et al. zeigten, dass die Cortisol Level in der Perilymphe des Innenohres einer Patientengruppe bei Gabe von $250 \mathrm{mg}$ Prednisolon im Gegensatz zu einer nicht mit Kortison behandelten Kontrollgruppe signifikant erhöht waren. Hingegen zeigte sich keine signifikante Steigerung der Cortisol Level in der Perilymphe des Innenohres bei Patienten, die mit $125 \mathrm{mg}$ Prednisolon behandelt wurden (Niedermeyer et al. 2003). Tierexperimentelle Studien zeigen, dass im Vergleich zu einer oralen oder intravenösen Darreichung deutlich höhere perilymphatische Kortikosteroidkonzentrationen durch die intratympanale Injektion erreicht werden. Gerade angesichts der möglichen Nebenwirkungen einer systemischen Kortikosteroidgabe ist dies von Nutzen und stellt eine adäquate alternative Applikationsform dar (Parnes et al. 1999; Chandrasekhar 2001; Rauch 2004; Hargunani et al. 2006). Daher wird der intratympanalen Applikation der Wirksubstanzen eine zunehmende Bedeutung zugesprochen. Die Studie von Parnes et al. hat gezeigt, dass die Steroidkonzentrationen in der Perilymphe bei Gabe von Hydrokortison, Methylprednisolon oder Dexamethason bei lokaler Gabe im Vergleich zu einer systemischen Applikation der Medikamente wesentlich höher lagen. Die Studie vergleicht zudem die intratympanale Applikation von Dexametason (4 mg/ml) mit Methylprednisolon (40 mg/ml) und Hydrokortison (50 $\mathrm{mg} / \mathrm{ml}$ ) und kommt zu dem Ergebnis, dass Methylprednisolon am längsten und in höchster Konzentration sowohl in der Peri- als auch in der Endolymphe nachgewiesen werden kann. In einer darauf aufbauenden klinischen Untersuchung zeigte sich zudem, dass bei etwas über einem Drittel der untersuchten Patienten (13 von 37) eine signifikante Hörverbesserung nach lokaler Medikamentenapplikation eintrat, wenn das Medikament binnen sechs Wochen nach Auftreten des Hörverlusts appliziert wurde. Es wird ein Therapieregime von wöchentlich zwei Injektionen 
einer Lösung aus 0,9 ml Methylprednisolon (40 mg/ml) mit 0,1 ml 1 \% Lidocain über drei Wochen vorgeschlagen (Parnes et al. 1999).

Zusammenfassend kann gesagt werden, dass der Nutzen einer Glukokortikoidtherapie zur Behandlung des akuten idiopatischen Hörverlusts nicht abschließend geklärt ist, sodass auch ein aktuelles Cochrane Review eine nur geringe Evidenz dieser Behandlungsstrategie bescheinigt (Wei et al. 2013). In der aktuellen S1 Leitlinie zum akuten idiopathischen sensorineuralen Hörverlust wird als Primärtherapie eine Glukokortikoid-Behandlung über mindestens 3 Tage mit jeweils 250 mg Prednisolon oder einem anderen synthetischen Glukokortikosteroid mit äquivalenter Dosierung empfohlen (Leitlinie Hörsturz 2014).

\subsection{Stärken, Limitierungen und Ausblick}

In der vorliegenden Arbeit konnte unter Verwendung eines Tiermodells für einen akuten vaskulär bedingten Hörverlust kein Wirksamkeitsnachweis einer Glukokortikoidtherapie erbracht werden. Die Versuchsreihe beschreibt einen Akutversuch, sodass mögliche Langzeiteffekte der Glukokortikoide nicht untersucht wurden. Akuteffekte, wie beispielsweise die antiödematöse Wirkung der Glukokortikoidbehandlung, scheinen jedoch keine Auswirkung auf die akute vaskulär bedingte Hörminderung zu haben. Der ausbleibende Therapieerfolg deckt sich zudem mit jenen klinischen Studien, die ebenfalls keinen Wirksamkeitsnachweis in ihren untersuchten Patientenkollektiven beschreiben (Cinamon et al. 2001; Nosrati-Zarenoe und Hultcrantz 2012).

Aus den vorliegenden Ergebnissen lässt sich die Notwendigkeit für alternative Therapiestrategien zur Behandlung des Hörsturzes ableiten. Wie in den Voruntersuchungen von Ihler et al. wurde der Zusammenhang zwischen akuter Hyperfibrinogenämie und der Entstehung eines akuten Hörverlusts tierexperimentell bestätigt. Neue Therapien könnten hier ansetzen. Kann beispielsweise der Hörsturz mittels einfacher Blutuntersuchung mit einer erhöhten Plasmafibrinogenkonzentration in Verbindung gebracht werden, erscheint ein gezieltes Eingreifen an der Stelle sinnvoller als die bisher in der klinischen Praxis durchgeführte Behandlung 
mit Kortikosteroiden. Der therapeutische Nutzen einer Apherese zur Reduktion pathologischer Plasmafibrinogenkonzentrationen wurde bereits in klinischen Studien dargestellt (Suckfüll und Hearing Loss Study Group 2002; Canis et al. 2012).

Einen Effekt auf eine fibrinogenbedingte Hörminderung könnte die in der vorliegenden Arbeit nicht untersuchte Langzeitwirkung einer Kortikosteroidbehandlung dennoch entfalten. Fibrinogen ist als Protein der akuten Phase nämlich vergesellschaftet mit systemischen inflammatorischen Prozessen. Der mit 120 Minuten zeitlich limitierte Akutversuch der vorliegenden Arbeit eignet sich jedoch nicht zur Untersuchung der antiinflammatorischen Wirkung einer andauernden Behandlung mit Glukokortikoiden. Die Untersuchungen müssten durch einen Versuchsaufbau mit einer Therapie über mehrere Tage bis Wochen erfolgen. In einem solchen chronischen Tierversuch ist die operative Darstellung der Stria vascularis und damit die selektive Betrachtung des cochleären Blutflusses einzelner Gefäße jedoch nicht möglich. Läge die Stria vaskularis für einen zu langen Zeitraum operativ exponiert, käme es zu Thrombosierungen, die eine zeitliche Limitierung dieser Experimente darstellt. Würde auf die Erhebung der Parameter zur cochleären Mikrozirkulation mittels Intravitalmikroskopie hingegen verzichtet, könnten die Messungen über einen längeren Zeitraum erfolgen.

Die Auswirkungen verschiedener Applikationsformen wurden in der vorliegenden Arbeit ebenfalls nicht untersucht. Eine vergleichende Studie zur systemischen Kortisongabe gegenüber der intratympanalen Anwendung oder einer Kombinationstherapie wäre ein denkbares Design. 


\section{Zusammenfassung}

\subsection{Deutsch}

Bis heute ist für den akuten idiopathischen sensorineuralen Hörverlust („Hörsturz") der zugrundeliegende Pathomechanismus nicht abschließend verstanden, und folglich ist auch die Evidenz zu kausalen Therapieoptionen unbefriedigend. In der vorgelegten Arbeit sollte daher im Tiermodell untersucht werden, ob der fibrinogenbedingte sensorineurale Hörverlust durch systemische Gabe von Glukokortikoiden, die den aktuellen Therapiestandard in Deutschland darstellen, zu behandeln ist. Dazu wurden zwei Versuchsgruppen gebildet und nach Induktion eines vaskulär bedingten Hörverlusts mittels akuter Hyperfibrinogenämie mit Methylprednisolon oder mit einer äquivalenten Menge isotonischer Kochsalzlösung als Placebo verblindet therapiert.

Mit dem signifikanten Anstieg der Plasmafibrinogenkonzentration ging ein signifikanter Anstieg der Hörschwelle einher. Ebenfalls war eine Reduktion des cochleären Blutflusses in den Kapillargefäßen der Stria vascularis zu erkennen. Die rheologischen Eigenschaften des Blutes lassen sich durch eine Hyperfibrinogenämie beeinflussen und scheinen mit einer Hörverschlechterung in unmittelbaren $\mathrm{Zu}$ sammenhang zu stehen. Bei den erhobenen Messparametern war nach Einleiten der experimentellen Therapie kein signifikanter Unterschied zwischen den beiden Versuchsgruppen zu verzeichnen. Im Versuchsverlauf blieb die Plasmafibrinogenkonzentration auf konstant hohem Niveau; eine Reduktion des cochleären Blutflusses und ein Anstieg der Hörschwelle waren zu beobachten. In dem der Arbeit zugrundeliegenden Akutmodell für einen vaskulär bedingten Hörverlust konnte für die Therapie mit Glukokortikoiden folglich kein Wirksamkeitsnachweis erbracht werden. 


\subsection{English}

Until today the pathogenesis of sudden sensorineural hearing loss (SSHL) remains unclear. Consequently, the evidence for causal therapeutic options is unsatisfactory.

The aim of this study was to investigate the effect of a corticosteroid infusion on acute hearing loss and inner ear microcirculation for vascular cochlear impairment since corticosteroids appear to be the current therapeutic standard for SSHL. For this purpose, two groups of guinea pigs were formed and, after induction of a SSHL by acute hyperfibrinogenemia, treated with either methylprednisolon or an equal amount of isotonic saline solution as placebo therapy.

Significant increase in the plasma fibrinogen concentration were accompanied by a significant increase in the hearing threshold. Furthermore, a decrease in cochlear blood flow in the capillaries of the stria vascularis has been detected. The rheological properties of the blood could be influenced by hyperfibrinogenemia and appear to be directly related to hearing impairment. There was no significant difference between the two groups after treatment with either methylprednisolone or placebo. During the experiment, the plasma fibrinogen concentration remained at a consistently high level, a reduction in cochlear blood flow and an increase in the hearing threshold were observed. Consequently, no proof of efficacy could be provided for therapy with glucocorticoids in the underlying acute model for vascular cochlear impairment. 


\section{Literaturverzeichnis}

Alexiou C, Arnold W, Fauser C, Schratzenstaller B, Gloddek B, Fuhrmann S, Lamm K (2001): Sudden sensorineural hearing loss: does application of glucocorticoids make sense? Arch Otolaryngol Head Neck Surg 127, 253-258

AWMF Online, Leitlinien der Deutschen Gesellschaft für Hals-Nasen-Ohren- Heilkunde, S1-Leitlinie HNO (2014) : Hörsturz (Akuter idiopathischer sensorineuraler Hörverlust) https://www.awmf.org/uploads/tx_szleitlinien/017010l_S1_Hoersturz_2014-02-verlaengert.pdf; Zugriff am 15.05.2016

Baker M, Wayland H (1974): On-line volume flow rate and velocity profile measurement for blood in microvessels. Microvasc Res 7 , 131-143

Bertlich M, Ihler F, Weiss BG, Freytag S, Jakob M, Strupp M, Pellkofer H, Canis M (2017): Fingolimod (FTY-720) is Capable of Reversing Tumor Necrosis Factor Induced Decreases in Cochlear Blood Flow. Otol Neurotol, 38, 12131216

Bianchin G, Russi G, Romano N, Fioravanti P (2010): Treatment with HELPapheresis in patients suffering from sudden sensorineural hearing loss: a prospective, randomized, controlled study. Laryngoscope $\underline{120}$, 800-807

Boenninghaus H-G, Lenarz T: Hals-Nasen-Ohren-Heilkunde. 12. Auflage; Springer, Heidelberg 2004

Boudarene M, Legros JJ, Timsit-Berthier M (2002): [Study of the stress response: role of anxiety, cortisol and DHEAs]. Encephale 28, 139-146

Byl FM (1977): Seventy-six cases of presumed sudden hearing loss occurring in 1973: prognosis and incidence. Laryngoscope 87, 817-825

Canis M, Heigl F, Suckfuell M (2012): Fibrinogen/LDL apheresis is a promising rescue therapy for sudden sensorineural hearing loss. Clin Res Cardiol Suppl 7 $36-40$

Chandrasekhar SS (2001): Intratympanic dexamethasone for sudden sensorineural hearing loss: clinical and laboratory evaluation. Otol Neurotol 22, 18-23

Cinamon U, Bendet E, Kronenberg J (2001): Steroids, carbogen or placebo for sudden hearing loss: a prospective double-blind study. Eur Arch Otorhinolaryngol 258, 477-480

Conlin AE, Parnes LS (2007): Treatment of sudden sensorineural hearing loss: I. A systematic review. Arch Otolaryngol Head Neck Surg 133, 573-581

Glacet-Bernard A, Roquet W, Coste A, Peyngre R, Coscas G, Soubrane G (2008): Central retinal vein occlusion and sudden deafness: a possible common pathogenesis. Eur J Ophthalmol 11, 197-199

Graumann W, Sasse D (Hrsg.): CompactLehrbuch Anatomie: in 4 Bänden. Schattauer Verlag, Stuttgart 2005 
Gross M, Wolf DG, Elidan J, Eliashar R (2007): Enterovirus, cytomegalovirus, and Epstein-Barr virus infection screening in idiopathic sudden sensorineural hearing loss. Audiol Neurootol 12, 179-182

Guyot JP, Thielen K (2000): [Evolution of sudden deafness without treatment]. Schweiz Med Wochenschr Suppl 116, 93S-96S

Hallberg OE (1956): Sudden deafness of obscure origin. Laryngoscope $\underline{66}, 1237-$ 1267

Hargunani CA, Kempton JB, DeGagne JM, Trune DR (2006): Intratympanic injection of dexamethasone: time course of inner ear distribution and conversion to its active form. Otol Neurotol 27, 564-569

Hesch RD (1982): [Therapeutische Überlegungen zu vaskulären Innenohrerkrankungen.]. HNO $\underline{30}, 365-374$

Hilger J (1952): Therapeutic approach to sudden deafness. Ann Otol Rhinol Laryngol $\underline{61}, 608-611$

Ihler F, Strieth S, Pieri N, Göhring P, Canis M (2012): Acute hyperfibrinogenemia impairs cochlear blood flow and hearing function in guinea pigs in vivo. Int J Audiol 51, 210-215

Ihler F, Sharaf K, Bertlich M, Strieth S, Reichel CA, Berghaus A, Canis M (2013): Etanercept prevents decrease of cochlear blood flow dose-dependently caused by tumor necrosis factor alpha. Ann Otol Rhinol Laryngol $\underline{122}$, 468473

Jaffe BF (1970): Sudden deafness--a local manifestation of systemic disorders: fat emboli, hypercoagulation and infections. Laryngoscope $\underline{80}, 788-801$

Jensen T, Kierulf P, Sandset PM, Klingenberg O, Joø GB, Godal HC, Skjønsberg OH (2007): Fibrinogen and fibrin induce synthesis of proinflammatory cytokines from isolated peripheral blood mononuclear cells. Thromb Haemost $\underline{97}$, 822-829

Kimura RS (1986): Animal models of inner ear vascular disturbances. Am J Otolaryngol $7,130-139$

Klemm E, Altmann E, Lange O (1983): Rheologische Probleme der Mikrozirkulation und Konsequenzen medikamentöser Hörsturztherapie. Laryngol Rhinol Otol (Stuttg) 62, 62-64

Klemm E, Deutscher A, Mösges R (2009): Aktuelle Stichprobe zur Epidemiologie des idiopathischen Hörsturzes. Laryngorhinootologie 88, 524-527

Konishi T (1979): Some observations on negative endocochlear potential during anoxia. Acta Otolaryngol $\underline{87}, 506-516$

Landier W (2016): Ototoxicity and cancer therapy. Cancer 122, 1647-1658 
Lamm K, Arnold W (1999): How useful is corticosteroid treatment in cochlea disorders. Otorhinolaryngol Nova $\underline{9}, 203-216$

Leitlinie Hörsturz siehe AWMF Online Leitlinie Hörsturz 2014

Lip GY (1995): Fibrinogen and cardiovascular disorders. QJM $\underline{88}, 155-165$

Lominadze D, Dean WL, Tyagi SC, Roberts AM (2010): Mechanisms of fibrinogeninduced microvascular dysfunction during cardiovascular disease. Acta Physiol (Oxf) 198, 1-13

Maass B (1982): Innenohrdurchblutung. Anatomisch-funktionelle Betrachtungen. HNO $\underline{30}, 355-364$

Mattox DE, Simmons FB (1977): Natural history of sudden sensorineural hearing loss. Ann Otol Rhinol Laryngol $\underline{86}$, 463-480

Michel O: Der Hörsturz. (Hrsg.) Georg Thieme Verlag, Stuttgart 1994

Mindedal H (2007): A Micro-miniature Sensor for In Vivo Pressure Measurement | Sensors. Verlag: Questex, Ort: Framingham/Newton, Zeitschrift: Sensors Magazin (Online) http://www.sensorsmag.com/specialtymarkets/medical/a-micro-miniature-sensor-in-vivo-pressuremeasurement-1326; Zugriff am 21.03.2016

Moskowitz D, Lee KJ, Smith HW (1984): Steroid use in idiopathic sudden sensorineural hearing loss. Laryngoscope $94,664-666$

Nakashima T (2003): Disorders of cochlea blood flow. Brain Res Brain Res Rev $\underline{43}$ $17-28$

Niedermeyer HP, Zahneisen G, Luppa P, Busch R, Arnold W (2003): Cortisol levels in the human perilymph after intravenous administration of prednisolone. Audiol Neurootol $\underline{8}, 316-321$

Nin F, Hibino H, Doi K, Suzuki T, Hisa Y, Kurachi Y (2008): The endocochlear potential depends on two $\mathrm{K}+$ diffusion potentials and an electrical barrier in the stria vascularis of the inner ear. Proc Natl Acad Sci USA 105, 1751-1756

Nosrati-Zarenoe R, Hultcrantz E (2012): Corticosteroid treatment of idiopathic sudden sensorineural hearing loss: randomized triple-blind placebocontrolled trial. Otol Neurotol $\underline{33}, 523-531$

Nuttall AL, Lawrence M (1980): Endocochlear potential and scala media oxygen tension during partial anoxia. Am J Otolaryngol 1 , 147-153

Olzowy B, Osterkorn D, Suckfüll M (2005): Hörsturz wesentlich häufiger als bisher angenommen. MMW Fortschr Med 147, 37-38

O'neill JJ (1960): Sudden unilateral hearing loss attributable to mumps. J Speech Hear Disord 25, 55-58 
Parnes LS, Sun A-H, Freeman DJ (1999): Corticosteroid Pharmacokinetics in the Inner Ear Fluids: An Animal Study Followed by Clinical Application. Laryngoscope $\underline{109}$, 1-17

Pitkäranta A, Julkunen I (1998): Sudden deafness: lack of evidence for systemic viral infection. Otolaryngol Head Neck Surg 118, 397-399

Rarey KE, Curtis LM (1996): Receptors for glucocorticoids in the human inner ear. Otolaryngol Head Neck Surg $\underline{115}, 38-41$

Rauch SD (2004): Intratympanic steroids for sensorineural hearing loss. Otolaryngol Clin North Am $\underline{37}, 1061-1074$

Scherer EQ, Yang J, Canis M, Reimann K, Ivanov K, Diehl CD, Backx PH, Wier WG, Strieth S, Wangemann P, et al. (2010): Tumor necrosis factor- $\alpha$ enhances microvascular tone and reduces blood flow in the cochlea via enhanced sphingosine-1-phosphate signaling. Stroke $\underline{41}$, 2618-2624

Sheu J-J, Keller JJ, Chen Y-H, Wu C-S, Lin H-C (2012): No increased risk of sudden sensorineural hearing loss following recent herpes zoster: a nationwide population-based study. Acta Otolaryngol 132, 167-172

Sigma Aldrich, Fluorescein isothiocyanate-dextran average mol wt 70,000, (FITC:Glucose $=1: 250$ ) http://www.sigmaaldrich.com/catalog/product/sigma/46945?lang=de\&re gion= DE; Zugriff am 05.08.2016

Suckfüll M, Hearing Loss Study Group (2002): Fibrinogen and LDL apheresis in treatment of sudden hearing loss: a randomised multicentre trial. Lancet $\underline{360}, 1811-1817$

Thalmann R, Miyoshi T, Thalmann I (1972): The influence of ischemia upon the energy reserves of inner ear tissues. Laryngoscope 82, 2249-2272

Van Dishoeck HA, Bierman TA (1957): Sudden perceptive deafness and viral infection; report of the first one hundred patients. Ann Otol Rhinol Laryngol $\underline{66}$, 963-980

Vasama J-P, Linthicum FH (2000): Idiopathic Sudden Sensorineural Hearing Loss: Temporal Bone Histopathologic Study. Ann Otol Rhinol Laryngol 109, 527532

Veltri RW, Wilson WR, Sprinkle PM, Rodman SM, Kavesh DA (1981): The implication of viruses in idiopathic sudden hearing loss: primary infection or reactivation of latent viruses? Otolaryngol Head Neck Surg $\underline{89}, 137-141$

Wei BP, Stathopoulos D, O'Leary S (2013): Steroids for idiopathic sudden sensorineural hearing loss; in: Cochrane Database Syst Rev 7, CD003998 
Wilson WR, Byl FM, Laird N (1980): The efficacy of steroids in the treatment of idiopathic sudden hearing loss. A double-blind clinical study. Arch Otolaryngol $\underline{106}, 772-776$ 


\section{Danksagung}

Mein besonderer Dank gilt Herrn Prof. Dr. Martin Canis für die freundliche Überlassung des Themas und die Möglichkeit der Promotion in seiner Abteilung.

Sehr herzlich bedanke ich mich bei Herrn Dr. med. Bernhard Weiss für die stetige freundschaftliche Zusammenarbeit. Als mein Betreuer unterstützte und motivierte er mich zu jeder Zeit und mit großem Engagement. Ohne ihn wäre die Arbeit nicht möglich gewesen.

Ganz herzlich möchte ich mich bei Herrn Dr. med. Mattis Bertlich sowie Herrn Priv.-Doz. Dr. med. Fritz Ihler bedanken. Ihre Hilfestellung beim Erlernen der komplexen chirurgischen Tätigkeit war eine wichtige Säule dieser Arbeit.

Ebenfalls danken möchte ich den Mitarbeiterinnen und Mitarbeitern der Abteilung für Klinische Chemie der Georg-August-Universität. Ihre stets freundliche Hilfestellung bei der Analyse der Blutproben hat zum Erfolg der Arbeit beigetragen. 
